\title{
Alfonso Reyes oder die Arbeit am Mythos
}

Was ist die „Arbeit am Mythos“? Welche theoretischen Implikationen birgt sie? Und wie kann ihr Verhältnis zu den zeithistorischen wie literarisch-künstlerischen Kontexten gedacht werden? Die literarische Verarbeitung und Umformung eines antiken Mythos lässt sich begreifen als ein Polylog, der sich zwischen dem (normativen) Vorbild, der späteren Bearbeiter^in dieses Modells und dem Mythos selbst entspinnt. Etwas präziser noch könnte man diese Beziehungen beschreiben als intertextuelle Auseinandersetzung mit und zwischen den einzelnen literarischen Konkretisationen des Mythos sowie den jeweiligen historischen, kulturellen, biographischen und literarästhetischen Kontexten dieser Werke.

Der Rückgriff auf und die Arbeit am Mythos setzt somit eine Vielzahl unterschiedlicher Texte und Kontexte zueinander in Bewegung, deren Wegen und Konfrontationen von der literaturwissenschaftlichen Analyse behutsam nachgegangen, und ohne Reduktion ihres Sinnpotentials nachgezeichnet werden muss. Daraus ergibt sich die Komplexität, aber auch Fruchtbarkeit derartiger Analysen für eine literatur- und kulturgeschichtliche Vorlesung. Zumal in Rechnung zu stellen ist, dass dieses Sinnpotential durch die Beziehung zum zeitgeschichtlichen Kontext der Autor`innen wie gerade auch der Leser`innen historisch immer neu entfaltet werden kann und muss.

Die Komplexität sowohl der literarischen Gestaltung des mythologischen Paradigmas als auch der nachfolgenden Spurensicherung und Auslegung wird noch wesentlich erhöht, wenn sich die intertextuellen Beziehungen nicht mehr nur innerhalb der europäischen Literaturen, sondern im Raum eines interkulturellen Polylogs bewegen. Dann lässt sich nämlich der Charakter eines asymmetrischen Gesprächs nicht nur hinsichtlich der Relation zwischen dem präsenten Text und seinen miteinbezogenen, aber nicht selbst gegenwärtigen Intertexten (dem Mythos und seinen späteren Bearbeitungen) konstatieren. Vielmehr prägt die Asymmetrie einen interkulturellen Polylog zwischen einem außereuropäischen Text und seinen europäischen Bezugstexten überhaupt, wenn diese Asymmetrie sich auch im Laufe der geschichtlichen und literarischen Entwicklungen in ihren Auswirkungen verändert hat und weiterhin verändert. ${ }^{1}$

In der gegenwärtigen literaturwissenschaftlichen Diskussion trägt man etwa im Zeichen transarealer Forschungen der Situation Rechnung, dass seit langer Zeit schon das literarische Erbe Europas nicht mehr ausschließlich Sache der

1 Vgl. Ette, Ottmar: Asymmetrie der Beziehungen. Zehn Thesen zum Dialog der Literaturen Lateinamerikas und Europas. In: Scharlau, Birgit (Hg.): Lateinamerika denken. Kunsttheoretische Grenzgänge zwischen Moderne und Postmoderne. Tübingen: Narr 1994, S. 297-326.

Ә Open Access. (C) 2021 Ottmar Ette, publiziert von De Gruyter. (c) BY-NC-ND Dieses Werk ist lizensiert unter einer Creative Commons Namensnennung - Nicht-kommerziell - Keine Bearbeitung 4.0 International Lizenz. https://doi.org/10.1515/9783110703450-009 
europäischer Autorinnen und Autoren ist. Sicherlich bietet am Ausgang des 20. Jahrhunderts der Übergang von einem System der Weltliteratur (noch im Sinne Goethes) zu einem System der Literaturen der Welt ${ }^{2}$ eine Vielzahl von Chancen und Möglichkeiten, die jahrhundertelange Asymmetrie der Beziehungen zu überwinden und in einer Phase viellogischer literarischer Systeme einzutreten. Doch wäre es selbst für unsere Gegenwartsliteraturen deutlich verfrüht, von einem weltliterarischen Paradigmenwechsel hinsichtlich einer Situation zu sprechen, innerhalb derer gleichberechtigte kulturelle und literarische Areas miteinander in einen Polylog auf Augenhöhe eintreten könnten.

Selbstverständlich war dies ein Jahrhundert früher auch für die damalige Produktion von Literatur etwa in Lateinamerika nicht der Fall. Aber das Versdrama des mexikanischen Autors Alfonso Reyes markiert doch eine Entwicklung auf dem Weg zu einem solchen (vielleicht utopischen) Zustand absolut gleichberechtigter Literaturen der Welt.

Denn im Bereich der lateinamerikanischen Literaturen lassen sich derartige Veränderungen spätestens seit dem letzten Drittel des 19. Jahrhunderts - also mit dem hispanoamerikanischen Modernismo - beobachten. Gerade die Untersuchung der literarischen Umsetzung von Mythen aus der griechisch-römischen Antike in Lateinamerika kann Aufschluss über Richtung und Problematik dieser Entwicklung geben, da die Mythen zu einem gewichtigen Teil des Fundaments der europäischen Literaturen ausmachen, zum anderen aber in ihrer Eigenschaft als soziale Gebilde eine Modellfunktion innehaben. Denn Mythen wohnt ein miniaturisierter Modellcharakter von Vorstellungen inne, die auf eine allgemeine, ja totale Weltdeutung hin ausgerichtet sind. Wer sich also mit dem Mythos einlässt, der muss sich - wie auch immer - mit dieser paradigmatischen Funktion von Weltdeutung auseinandersetzen.

Zweifellos hat im 19. und 20. Jahrhundert das Exil zahlreicher lateinamerikanischer Schriftsteller den Prozess eines Abbaus von Asymmetrien im literarischen System begünstig. Insofern kann die individuell oft tragische Bedeutung des Exils auf einer (literatur-)soziologischen Ebene durchaus Veränderungen im literarischen System bewirken und die Wichtigkeit der erzwungenen oder freiwilligen Entfernung als Beschleunigungsfaktor von Ausgleichprozessen unterstreichen. Auch das in freien Versen geschriebene dramatische Gedicht Ifigenia cruel des mexikanischen Schriftstellers, Literaturtheoretikers und Diplomaten Alfonso Reyes war ein Produkt des Exils. Im August und September 1923 in Deva und Madrid geschrieben, 1924 in der spanischen Hauptstadt erstveröffentlicht, fällt

2 Vgl. Ette, Ottmar: WeltFraktale. Wege durch die Literaturen der Welt. Stuttgart: J.B. Metzler Verlag 2017. 
es in eine Zeit, in der sich (etwa seit 1920) die prekäre Situation von Reyes im Exil wieder zu stabilisieren und normalisieren begann: Der junge Mexikaner hatte wieder Boden unter den Füßen.

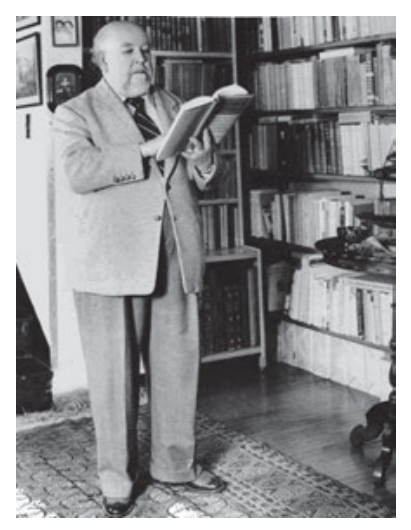

Abb. 52: Alfonso Reyes (Monterrey, 1889 - Mexiko-Stadt, 1959).

Der Aufenthalt des Mexikaners in Europa hatte mit dem fast fluchtartigen Verlassen Mexikos im August 1913 begonnen, als er sich nach dem gewaltsamen Tod seines Vaters, des Generals Reyes, zum zweiten Sekretär der mexikanischen Gesandtschaft in Paris ernennen ließ und, „con su poquillo de destierro honorable“, ${ }^{3}$ folglich „mit einem Wenigen an ehrenhaftem Exil“, mit Frau und Kind nach Frankreich aufbrach. Schnell war durch die Auflösung des diplomatischen Corps im Gefolge der Mexikanischen Revolution nach der Machtergreifung Carranzas die unsichere Lage in der Tat zum Exil geworden, schnell aber auch war Reyes zuerst in Frankreich, dann in Spanien mit französischen und spanischen, vor allem aber auch mit lateinamerikanischen Intellektuellen in enge Verbindung getreten. In Paris und später Madrid waren es nicht zuletzt diese Kontakte mit Schriftstellern und Forschern wie Lugones, Alcides Arguedas, Larreta, mit Valery Larbaud, Menéndez Pidal, Américo Castro, Federico de Onís und vielen anderen, die seine Sichtweise Amerikas veränderten. Auch auf der Ebene dieser Exilgemeinschaften lässt sich die Geschichte der lateinamerikanischen Diaspora vor allem auch in Europa als recht fruchtbar ansehen.

Ein solchermaßen internationalisierter Kulturhorizont, den das Exil in Reaktion auf politische Konjunkturen ebenso rhythmisch wie fatal verstärkte, diente

3 Alfonso Reyes: Historia documental de mis libros. Universidad de México 1955), IX, no. 7; hier zitiert nach Iduarte, Andrés: Alfonso Reyes: vida y obra. In: Alfonso Reyes: vida y obra - bibliografia - antologia. New York: Hispanic Institute 1956, S. 26. 
Reyes als literarischer Lebensraum und Orientierung. Von Anfang an nahm er eine wichtige Vermittlerposition und Brückenfunktion zwischen Europa und Lateinamerika und damit zwischen unterschiedlichen kulturellen Areas ein. Aus dem Jahr 1914 bereits stammen die ersten Artikel für mexikanische und kubanische Zeitschriften. Diese Vermittlertätigkeit wird der Diplomat und Schriftsteller später in Buenos Aires und Rio de Janeiro fortsetzen und noch intensivieren. Er berichtete zunächst von neueren Entwicklungen des literarischen Lebens in Europa, wurde aber auch nicht müde, den Europäern wiederum Geschichte und Kultur der lateinamerikanischen Länder zu vermitteln, so dass man ihn bald in Paris den „Docteur des Amériques latines“ nannte. Alfonso Reyes hatte seine neue Funktion in einem transarealen Kontext gefunden.

Sein intellektuelles Hauptanliegen kreiste um die Frage, wie die lateinamerikanische Kultur und Literatur aus einer noch eher marginalen Rolle in den kulturellen Horizont Europas, ja einer weltumspannenden Kultur insgesamt, integriert und weitaus positiver ihrem Wert gemäß eingeschätzt werden könne. Mit dem Modernismus und der in Europa alle anderen weit überragenden Figur des nikaraguanischen Dichters Rubén Darío war man sich in der Alten Welt zum ersten Mal der Existenz einer lateinamerikanischen Literatur bewusst geworden. Mit steigendem Selbstbewusstsein verwies Alfonso Reyes auf das stetig wachsende Gewicht der spanischsprachigen Literaturen innerhalb eines weltliterarischen Systems. So schrieb er in einem Text aus dem Jahre 1941 dann bereits:

Die spanischsprachigen Literaturen Europas und Amerikas stellen keine bloße Kuriosität dar, sondern bilden einen essentiellen Bestandteil in der Überlieferung der menschlichen Kultur. Wer sie nicht kennt, ignoriert zumindest so viel, dass er die Möglichkeiten des Geistes nicht in ihrer Fülle verstehen kann, so viel, dass sein Bild von der Welt eine schreckliche Verstümmelung darstellt. ${ }^{4}$

Diese durchaus stolzen, aber legitimen Überlegungen von Alfonso Reyes waren der Ausdruck eines wachsenden Selbstvertrauens der lateinamerikanischen Literaturen in der ersten Hälfte des 20. Jahrhunderts, noch vor dem sogenannten ,Boom‘ der lateinamerikanischen Literatur weltweit. Die Entstehung des „poema dramático“ mit dem Titel Ifigenia cruel muss im Kontext einer literarischen Entwicklung angesiedelt werden, die Carlos Solórzano als „Theater universeller Tendenz" bezeichnet hat: ${ }^{5}$ die Suche nach allgemeinen, universalen, die ganze Menschheit betreffenden Themenstellungen. Denn ab etwa 1920 machte sich ver-

4 Reyes, Alfonso: Obras Completas. Bd. XI. México: Fondo de Cultura Económica 1959, S. 130. 5 Solórzano, Carlos: EI teatro de tendencias universales. In (ders.): Teatro latinoamericano en el siglo XX. México: Editorial Pormaca 1964, S. 53 ff. 
stärkt eine Rückbesinnung auf den Mythos, auf die Themen des antiken Theaters bemerkbar. Eine Bewegung, die sich zunächst mit den Namen wie Miguel de Unamuno, Jean Giraudoux, Eugene O’Neill oder Jean Cocteau verband, von Europa aber schnell nach Lateinamerika übersprang, wo bereits im Modernismo ebenso in der Lyrik wie in der Prosa antike Themen griechisch-römischer Provenienz Konjunktur gehabt hatten.

Alfonso Reyes war freilich mit Blick auf das antike Theater und die Beschäftigung mit der abendländischen Mythologie kein Anfänger mehr. Seine Auseinandersetzung mit der griechischen Antike reichte in die Zeit ersten literarischen Engagements zurück, als er sich ab 1906 im Umkreis der Zeitschrift Savia Moderna und danach in der Gruppe des Ateneo de la Juventud zusammen mit Antonio Caso, José Vasconcelos und vor allem Pedro Henríquez Ureña förmlich auf die griechische Antike stürzte. Dies bedeutete freilich nicht, dass er in seinem Einsatz für die mexikanische Literatur erlahmt wäre! Aus dem Jahre 1908 stammt denn auch die erste Beschäftigung mit der Figur Iphigenies in der kenntnisreichen Studie des noch nicht Zwanzigjährigen mit dem Titel Las tres Electras del teatro ateniense.

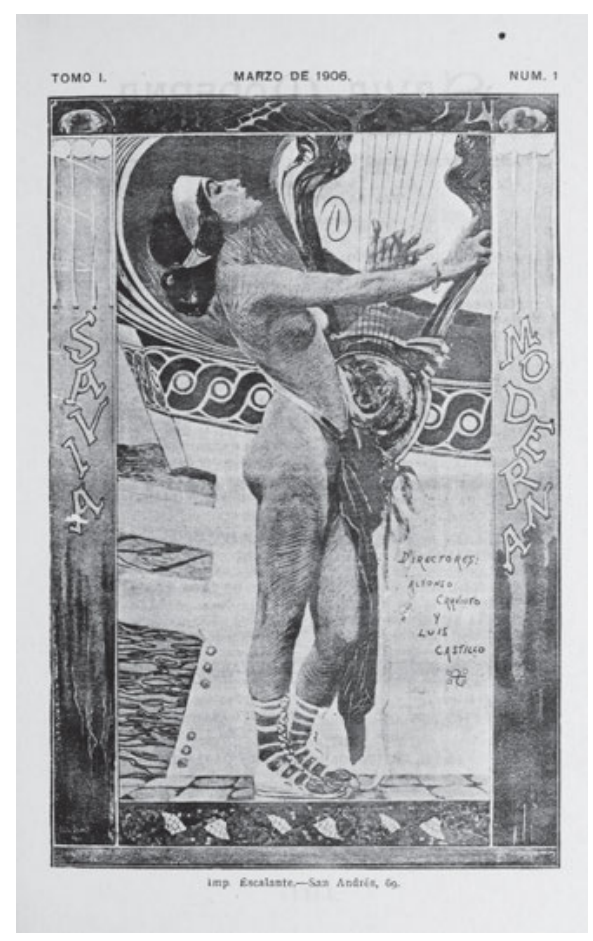

Abb. 53: Titelseite der Zeitschrift Savia Moderna, erste Ausgabe, 1906. 
Die Entstehung von Ifigenia cruel, im Übrigen das einzige Theaterstücks des Mexikaners, reichte also über einen Zeitraum von anderthalb Jahrzehnten zurück und beruhte auf einem langjährigen Studium der griechischen Antike. Ich möchte Ihnen gerne an dieser Stelle bereits eine Passage aus der Breve noticia a Ifigenia einspielen, die der junge Alfonso Reyes seinem Stück voranstellte und der älter gewordene Reyes in einer schönen Aufnahme selbst rezitierte. Dieses Tondokument verdiente, wie auch andere dieses Mexikaners, eigentlich eine gesonderte Beschäftigung mit der phonotextuellen Klang-Text-Relation, die freilich im Rahmen der schriftlichen Fassung dieser Vorlesung entfallen muss:

Im Unterschied zu allen, welche dieses Thema seit Griechenland bis in unsere Tage bearbeitet haben, nehme ich hier an, dass die von der Göttin Artemis aus den Händen des Opfernden in Aulis entrissene Iphigenie ihr erstes Leben vergessen hat und nicht weiß, wie sie auf Tauris zur Priesterin des barbarischen und grausamen Kultes ihrer Schutzgöttin geworden ist. Der tragische Konflikt, den keiner der vorherigen Dichter so deutete, besteht für mich eben darin, dass Iphigenie ihr Erbe an menschlichen Erinnerungen einfordert und Angst davor hat, sich als Waisenkind ihrer Vergangenheit und als von den anderen Geschöpfen abweichend zu fühlen; als später aber ihre Erinnerung wieder zu ihr kommt und sie versteht, dass sie einer blutbefleckten und vom Fluch der Götter verfolgten Rasse angehört, empfindet sie Ekel vor sich selbst. Schließlich vor die Alternative gestellt, sich entweder von neuem in die Tradition ihres Hauses zu stellen und die Vendetta von Mykene anzunehmen, oder weiterhin unter Barbaren zu leben und ein Leben als Zerfleischerin und Schlächterin heiliger Menschenopfer zu führen, zieht sie dieses letztere Extrem vor, so grässlich und hart es auch immer erscheinen mag, da es das einzig sichere und praktikable Mittel ist, jene Ketten zu vermeiden und zu brechen, welche sie an die Fatalität ihrer Rasse schmieden.

Die erste Zeit dieses Gedichts, welche ich bevorzuge und die mir besser geglückt scheint, stellt den Seelenzustand von Iphigenie vor, die ihre Vergangenheit vergessen hat, terrorisiert und überrascht davon, sich gegenüber den Frauen von Tauris anders zu fühlen, die sie ihrerseits mit einem gewissen religiösen Schrecken betrachten und vergebens zu lieben suchen. Das genetische Thema der griechischen Tragödie - der Chor, der in einem Kreistanz den Gott oder Heros hervorbringt oder durch viele Anrufungen erscheinen lässt - erhält plötzlich einen neuen Sinn; Iphigenie fordert vom Chor von Frauen, die allesamt und in der Hitze ihrer vereinigten Seelen wie ihrer Erinnerungen für sie eine menschliche Vergangenheit erschaffen, die natürliche Substanz ein, die ihr fehlt. Das Wunder geschieht allein durch Stellvertreterschaft: ihren Bruder Orest, der an die Küste von Tauris gelangt. ${ }^{6}$

Die „reescritura“ des griechischen Mythos und seiner früheren Bearbeitungen durch Alfonso Reyes war wohlüberlegt und klug durchdacht: Er akzentuierte nicht den Bruch mit den früheren Traditionssträngen, ließ aber keinen Zweifel daran, völliges Neuland betreten und damit eine nachvollziehbar avantgardistische Position eingenommen zu haben. Ein solches Verständnis von Avantgarde

6 Reyes, Alfonso: Breve noticia a Ifigenia cruel. In (ders.): Obras Completas, Bd. X, S. $313 \mathrm{f}$. 
bezog sich freilich auf die Uminterpretation des Mythos und auf dessen inhaltliche Umakzentuierung, nicht aber auf die literarische Form seines Versdramas. Auch ist dieser ostentative Bruch mit der Tradition keineswegs das Hauptanliegen des mexikanischen Schriftstellers.
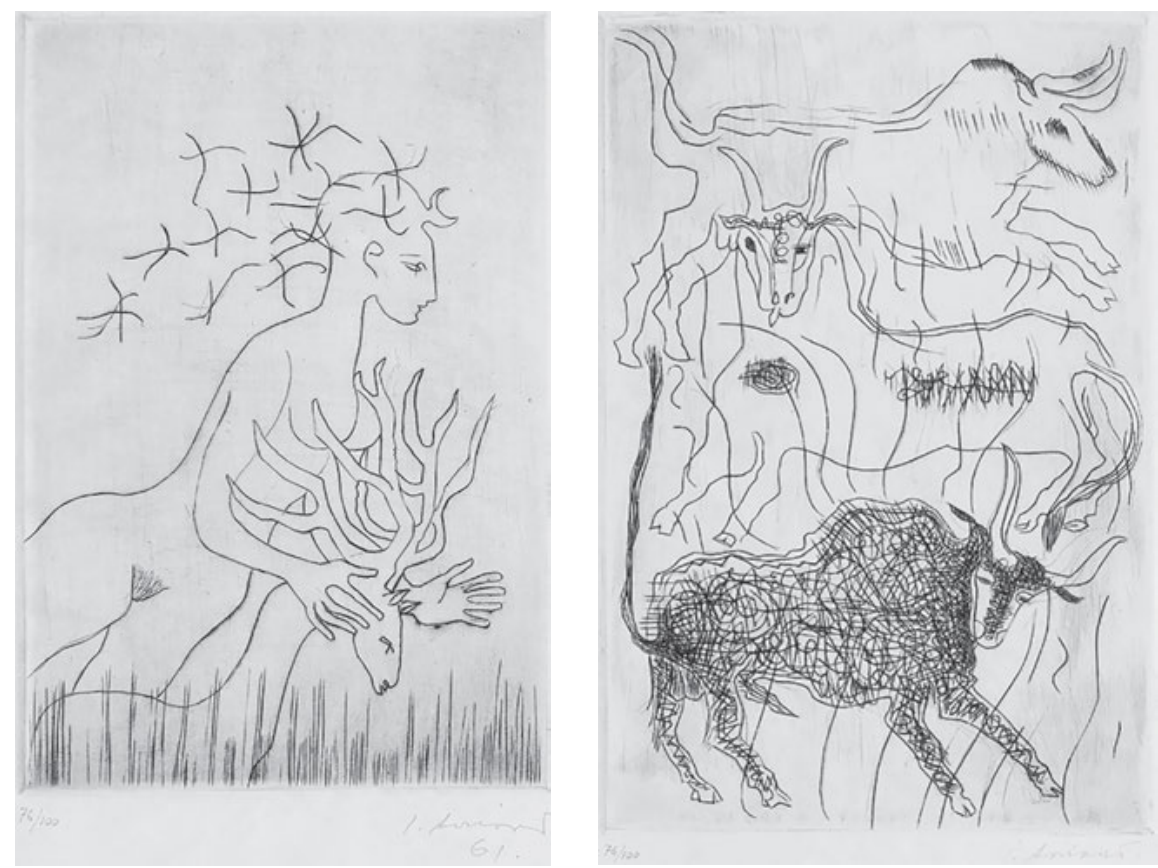

Abb. 54a und b: Juan Soriano: Zeichnungen für Ifigenia Cruel, 1961.

Die Beschäftigung mit Griechenland war, wie Alfonso Reyes später in seinem Kommentar zur Ifigenia cruel schrieb, für ihn geradezu lebensrettend. ${ }^{7}$ Es ging Reyes, der als Autodidakt zu einem der einflussreichsten Hellenisten Lateinamerikas wurde, auch keinesfalls um ein museales, akademisches Wissen, sondern vielmehr um eines, das sich im direkten Dialog mit dem Leben weiß: Nicht um wissenschaftliche Fußnoten, sondern um die großen Zusammenhänge, nicht um Dokumentarisches, sondern um Lebendiges war es ihm bei seiner Vermittlung der griechischen Antike zu tun. Ingemar Dürings Einschätzung ist insgesamt zuzustimmen, dass Reyes' Studien weniger durch ihre Originalität als durch ihre

7 Vgl. Reyes, Alfonso: Obras Completas, Bd. X, S. 351. 
Ausdrucksschärfe und brillante Anschaulichkeit herausragend seien. ${ }^{8}$ Als entscheidend für die Konzeption dieses theatralischen Gedichts erwies sich eines: Es war Alfonso Reyes um eine möglichst hochgradige Aufladung mit seinem persönlichen, individuellen Lebenswissen und Überlebenswissen zu tun.

Der Umgang mit der Antike als etwas Lebensnahem, ja Alltäglichem gibt den Arbeiten von Reyes eine Geschmeidigkeit und Freiheit, die sich in seiner kreativen Bearbeitung des Iphigenie-Stoffes wiederfinden. Dabei unterstrich er in seinem Selbstkommentar auch nachdrücklich sein Recht auf einen freien Umgang mit den antiken Stoffen: „Einmal im Besitz eines Moduls, auf welchem Wege auch immer, haben wir das Recht, es nach unserem Gutdünken zu manipulieren."9 Durch einen geradezu familiären Umgang mit dem abendländischen Kulturerbe soll „ein winziges Griechenland zu unserem Gebrauch: mehr oder minder dem Paradigma treu, aber immer Griechenland und immer unser“ entstehen. ${ }^{10}$

So fällt auch bei Alfonso Reyes jener Begriff „nuestra Grecia“, der im hispanoamerikanischen Modernismo und insbesondere bei José Martí eine wichtige Rolle spielte, was der Martí-Kenner Reyes sehr wohl wusste. Doch bei Reyes wird dabei weniger der Bezug auf die eigenen, präkolumbischen Kulturen Amerikas gesucht, weniger also eine Beziehung zu den Kulturen der Tolteken oder der Azteken hergestellt, sondern vielmehr auf eine individuell und schöpferisch anverwandelte griechische Antike angespielt, um diese für die lateinamerikanischen Literaturen verfügbar, ja manipulierbar zu machen.

$\mathrm{Zu}$ dieser Beziehung des antiken Mythos auf die zeitgenössische lebensweltliche Aktualität - und damit auf jene von den Avantgardisten eingeforderte Lebenspraxis - hören wir noch einmal die Stimme des mexikanischen Essayisten, Dichters und Dramaturgen:

Zum einen der Kampf Iphigenies zwischen der brüderlichen Zärtlichkeit und der Süße jugendlicher Erinnerungen, Affekten und familiären Beunruhigungen aus anderen Tagen was meiner hochfahrenden und grausamen Persönlichkeit eine momentane Sanftmut vermittelt - und zum anderen der Furcht, sich als Spross dieses verfluchten Zweiges zu fühlen. Wenn es zu Beginn, wie man bemerkt, Orest ist, der erzählt, so wird es danach sie sein, die seine Erzählung vervollständigt.

Man merke auf, dass es meine Anagnorisis oder Bewusstwerdung (mithin das Wiedererkennen beider Helden) ist, das einen tiefen Sinn erhält. In den Versionen der Athener Tragödie

8 Vgl. Düring, Ingmar: Alfonso Reyes helenista. In: Instituto Ibero-Americano de Gotemburgo. Madrid: Insula 1955, S. 9 ff.

9 Vgl. Reyes, Alfonso: Obras Completas, Bd. X, S. 351: „Tenemos derecho - una vez que por cualquier camino alcanzamos la posesión de un módulo - para manej arlo a nuestra guisa.“

10 Ebda., S. 352: „una minúscula Grecia para nuestro uso: más o menos fiel al paradigma, pero Grecia siempre y siempre nuestra.“ 
wissen Orest und Iphigenie sehr wohl, wer sie sind, und sie erkennen sich wechselseitig wieder. In meiner Interpretation hingegen kennt Iphigenie sich nicht, und sie identifiziert sich selbst erst in dem Augenblick, als sie Orest wiedererkennt. Die Anagnorisis greift auf eine andere innere Ebene hinunter, wenn bei Sophokles Ödipus entdeckt, dass er der Mörder seines Vaters ist und der Ehemann seiner eigenen Mutter, Zusammenhänge also, von denen er zuvor nichts ahnte.

Wenn Iphigenie sich für die Freiheit entscheidet und, sagen wir es so, sich dazu durchringt, ihr Leben in Bescheidenheit wiederaufzubauen, wobei sie den Verfolgungen und politischen Hasstiraden ihres Landes ein „Bis hierher!“ entgegenschleudert, so fädelt sie in gewisser Weise damit die Erlösung ihrer Rasse ein, wobei sie Verfahren zur Anwendung bringt, die aus philologischer Sicht hellenisch fragwürdig sind - obwohl es auch in der griechischen Lyrik Momente gibt, in welchen das intime Ich sich gegen die ethnisch-religiösen Symbole auflehnt und diese gar im Namen persönlicher Freiheit herausfordert -, doch sind dies Verfahren, welche in einfacher, direkter Form und in einem kurzen, präzisen Willensakt sehr wohl, so glaube ich, vielen Abergläubischen unserer Tage Erleichterung verschaffen könnten. ${ }^{11}$

Dieser schöpferische Umgang mit dem antiken Modell wird von Anfang an anhand einiger wesentlicher Eingriffe in den Mythos deutlich - und zugleich auch in den Kommentaren des mexikanischen Autors reflektiert: Reyes' lphigenie hat, als sich der Vorhang hebt und den Blick auf Tauris freigibt, ihr Gedächtnis verloren. Wie in einem „zweiten Leben“ - so Reyes’ Formulierung von 1908 -, ihrer Herkunft unbewusst und nur von einer dunklen Ahnung überschattet, verdankt sie sich allein der Göttin Artemis, der sie als Priesterin dient und alle Fremdlinge von eigener Hand opfert. Artemis ist Iphigeniens Schutz und ihre Zuflucht, zugleich aber auch jene Macht, die sie von ihrer Vergangenheit trennt.

Als ein solcher Fremdling kommt Orest, begleitet von seinem Freund Pylades, nach Tauris, wird sogleich gefangen genommen und soll - so will es das Gesetz von lphigenie alsbald geopfert werden. Orests Auftauchen aber, seine wortreiche und frei gestaltete Theogonie, bricht mit ihrer Namenskette in lphigenies Gedächtnis förmlich ein: „Die Namen, die Du aussprichst, brechen ein in meine Stirn." ${ }^{12}$ Die sich anschließende Anagnorisis, das Wiedererkennen der beiden Geschwister, konfrontieren die „Geopferte und Opfernde“13 mit ihrem ersten Leben, dessen Blutspur zuvor im Dunkel lag: „Ich erkenne mich in Deiner blutigen Geschichte wieder.“14

11 Ebda., S. $315 \mathrm{f}$.

12 Reyes, Alfonso: Obras Completas, Bd. X, S. 339: „Los nombres que pronuncias irrumpen por mi frente.“

13 Ebda., Bd. X, S. 34: „sacrificada y sacrificadora.“

14 Ebda., Bd. X, S. 339: „me reconozco en tu historia de sangre.“ 
In der Herrschaft des Bruders (und damit des Mannes) über die Schwester (und damit die Frau), in der nach Bachofens Interpretation der Orestie die Ablösung des Mutterrechts durch das Vaterrecht mitschwingt, spiegelt sich die Herrschaft des alten Lebens, der griechischen Herkunft, über die Gegenwart im Barbarenlande. Doch sie ist nur von kurzer Dauer - und eben darin liegt der eigentliche Clou von Reyes’ „Arbeit am Mythos“! In einer unerwarteten Wendung weist lphigenie ihre Heimführung nach Griechenland, die Reduzierung ihres Lebens auf die Aufgaben einer Frau im Hause, in der blutigen Geschichte der Atriden entschlossen zurück. Sie entbindet sich von dieser Geschichte, indem sie sich ein letztes Mal an Orest wendet, der sich seiner Sache schon sicher glaubte.

\footnotetext{
OREST: Und was wirst du tun, Torin, um die Silben jenes Namens, den du erleidest, zu brechen?

IPHIGENIE: Gering meine Tugend, gering mein Wille! Ein Vögelchen bin ich, zwischen Worten gefangen! Wenn die Einbildungskraft, von Phantasmen gebläht, nicht mehr vom Schiffe umzukehren weiß, das dich wegführt, wird mich meines Körpers Treue zu Füßen der Artemis zurückhalten, wo ich als Sklavin wiedergeboren werde.

Du wirst eine Stimme rauben, du wirst ein Echo retten; ein Bedauern, kein Begehren.

Nimm mit in deinen Händen, von deinem klugen Geiste genommen, diese beiden leeren Muscheln meiner Worte: Ich bleibe $!^{15}$
}

Iphigenie, kaum der Erinnerung an ihre Geschichte innegeworden, befreit sich von letzterer gerade nicht durch Verdrängung und Vergessen - was nur ein Aufschub vor der Freud'schen „Wiederkehr des Verdrängten“ wäre -, sondern in einem Akt, für den es in der langen Geschichte der Behandlung des IphigenieStoffes keine Referenzpunkte und keine Vorbilder gibt. Sie flüchtet sich in den Tempel, kehrt nicht mit ihrem Bruder Orest in die alte Heimat zurück, sondern verbleibt im Taurerland, im Barbarenland.

Damit ist die zyklische Bewegungsstruktur, auf der die Stoffgeschichte der taurischen Iphigenie, aber letztlich auch ein Gutteil des kulturellen Fundaments der lateinamerikanischen Literaturen bis hin zum Modernismo beruhte, durchbrochen: Der Kreis ist zerstört, die Linie ist an seine Stelle getreten, eine Rückkehr in die alte Geschichte, in die Alte Welt, wird, aller Verlockungen und Drohungen zum Trotz, rundweg abgelehnt. Es kommt zu keiner Rückkehr Iphigeniens in ihre

15 Ebda., Bd. X, S. 348 (Der letzte Ausruf lautet „No quiero“, eigentlich „Ich will nicht“). 
,Alte Welt', die griechische Zivilisation, deren Geschichte freilich so blutig ist. Wo stehen hier die ,Zivilisierten ${ }^{\text {‘ }}$ und wo die ,Wilden'? ${ }^{16}$ Die Bewegung des Verstehens wird anhand der Bewegung im Raum konkretisiert: Das „No quiero“ steht hier für den Bruch mit einer Geschichte, aus deren Herrschaft und Gewalt kein Weg herauszuführen schien. Iphigenies Entschluss ist frei gefasst, folgt ihrem freien Ermessen, einem für die Generation des Ateneo de la Juventud zentralen Konzept. $^{17}$

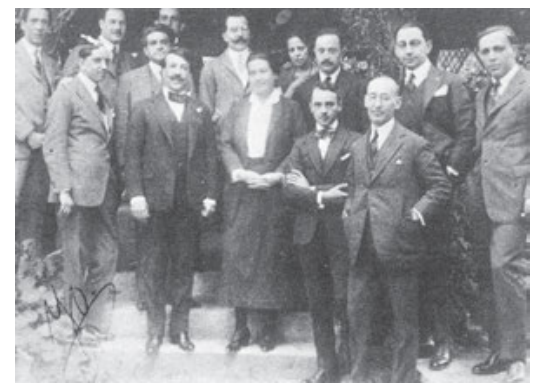

Abb. 55: Gruppe des Ateneo de la Juventud Mexicana, 1923.

Der scheinbar überzeugenden (und letztlich phallogozentrischen) Argumentation Orests setzt die ihm ,natürlich“ untergeordnete Schwester nicht nur ein Gegenargument, sondern vor allem ihren Körper entgegen, der sie zum Bleiben und damit zum Bruch mit der eigenen blutigen Geschichte veranlasst. Dabei schließt ihre Weigerung sehr wohl die Einsicht mit ein, dass sie als Sklavin ihrer Göttin nur ihren Weg aus der blutigen Geschichte ihrer Vorväter finden wird, als Sklavin und „sacerdotisa“, als Opfernde. Sie schlägt sich damit zugleich auf die Seite der Frauen und deren Schutzgöttin Artemis, ein fundamentaler rebellischer Akt, welcher in der Orestie nicht nur unerhört ist, sondern ihr eine gänzlich andere Richtung gibt. Das „no quiero“ verweist auf den großen Willen dieser Grausamen: sie bleibt nicht einfach, sie will nicht zurück, sie treibt kein solches Begehren („deseo“), sich wieder in diese alte Geschichte ein- und in dieser Tradition als Frau unterzuordnen. Iphigenie vertraut sich nicht der Macht der Männer, sondern der Sphäre des Göttlichen und, mehr noch, einer Göttin, ihrer Schutzgöttin, an: Artemis! Damit scheint eine fundamental emanzipatorische Bedeutung auf, welche in diesem Stück zumindest impliziert ist und über ein enormes Potenzial verfügt. Dem Autor muss diese im politischen Sinne avantgardistische Position

$16 \mathrm{Zu}$ dieser Opposition vgl. die klassische Studie von Bitterli, Urs: Die „Wilden“ und die „Zivilisierten“. Die europäisch-überseeische Begegnung. München: Deutscher Taschenbuch Verlag 1982. 17 Vgl. Sefchovich, Sara: México: país de ideas, país de novelas. Una sociología de la literatura mexicana. México - Barcelona - Buenos Aires: Grijalbo 1987, S. 80 f. 
nicht in allen Konsequenzen bewusst gewesen sein, um doch in jeglicher Hinsicht künstlerisch vollendet gestaltet zu werden: Ein Kunstwerk geht stets über die Absichten, über die Intentionen seiner Urheberinnen und Urheber hinaus und entbindet seine Möglichkeiten im Verlaufe einer langen Wirkungsgeschichte.

Ramón Xirau hat in einer einflussreichen Deutung versucht, die Gesamtentwicklung des Stückes pointiert auf einen Nenner zu bringen: „Ifigenia cruel: vom Vergessen der Ursprünge zum Gedächtnis, vom Gedächtnis zur willentlichen und hellsichtigen Entscheidung; von der Entscheidung und der Hellsichtigkeit zur Freiheit." ${ }^{18}$ Der Weg zur Freiheit führt über Erinnerung, Bewusstwerdung und Entschluss: So einleuchtend diese bündige Zusammenfassung auch sein mag, eine solche Interpretation verdeckt das Stück mit den Schleiern des Individualpsychologischen und Ontologischen, so dass die Grausame Iphigenie vorrangig auf die Dimensionen eines Seelendramas reduziert und als solches auch rezipiert wurde. Dies ist eine durchaus mögliche Deutung von Reyes' Ifigenia cruel, reduziert die literarisch-künstlerischen Ausdrucks- und Deutungsmöglichkeiten aber doch in einem erheblichen Maße.

Gewiss sind Alfonso Reyes' eigene Kommentare und Auslegungen, die eine wichtige paratextuelle, das Lesepublikum orientierende Funktion ausüben, nicht ganz unschuldig an dieser Lesart! Wir haben selbst anhand zweier Zitate oben gesehen, wie sorgfältig der mexikanische Schriftsteller gerade diese Dimensionen seines Stückes offengelegt hat. Absichtsvoll hatte Reyes einer ersten Lesung bereits einen „Kurzen Kommentar“ vorausgehen lassen, der später zusammen mit einem ausführlichen „Kommentar zu Ifigenia cruel“ die Ausgabe letzter Hand in seinen Obras Completas förmlich rahmt. Doch sollten wir uns in unserer Auslegung von Reyes' Versdrama nicht an die engen Grenzen dieser eigenen Deutung durch den Literaten halten, sondern zusätzliche Bedeutungsebenen (oder Isotopien) entfalten. Denn auch hier gilt, dass die Künstlerintentionen wichtige Kontexte für die Deutung eines literarischen Textes oder Kunstwerks vorgeben, aber keineswegs gleichbedeutend sind mit den geradezu unerschöpflichen Möglichkeiten, die der literarische Text selbst für zahlreiche Deutungsvariationen in der Zukunft offeriert.

In seinen Kommentaren hatte Reyes unmissverständlich auf den zweifellos wichtigen autobiographischen Hintergrund des Stückes aufmerksam gemacht, ${ }^{19}$ auf sein freiwilliges Exil, durch das er der fast zwangsläufigen Rache für seinen ermordeten Vater und damit einer Fortsetzung der blutigen Familiengeschichte

18 Xirau, Ramón: Cinco vías a „Ifigenia cruel“. In: Presencia de Alfonso Reyes. Homenaje en el X aniversario de su muerte (1959-1969). México: Fondo de Cultura Económica 1969, S. 164.

19 Reyes, Alfonso: Obras Completas, Bd. X, S. 354. 
ausgewichen war. Eine ganze Reihe autobiographischer Anspielungen im Text verweist unzweifelhaft auf diese Bedeutungsebene, ${ }^{20}$ die von der Literaturwissenschaft gerne aufgegriffen und belegt worden ist. So findet sich eine Vielzahl von Äußerungen Reyes’ zu dieser autobiographischen Dimension des Stückes etwa bei Melia Sánchez, ${ }^{21}$ aber auch in anderen, gerade die autobiographischen Aspekte betonenden Deutungsansätzen. Wir sollten uns freilich damit nicht zufrieden geben!

Eine andere Deutungslinie von Ifigenia cruel sah hinter diesem Autobiographischen das allgemein Menschliche aufscheinen, ganz im Sinne Alfonso Reyes', der nicht müde wurde, sein Verständnis der griechischen Tragödie in Konkordanz mit dem Zeitgeist in Europa als universales, sozusagen archetypisches Grundmuster zu erläutern. Der Iphigenie-Mythos löste so die Aufgabe jeglicher Arbeit am Mythos ein, fundamentale Modelle des Menschseins vor Augen zu führen und sinnlich-ästhetisch dem Publikum als solche zu präsentieren. So betonte der mexikanische Dichter und Essayist stets, die antike Tragödie sei nach seinem Verständnis „menschlich, aber weltweit menschlich (,universalmente humana'), insoweit sie den Menschen in den Rahmen der sein Wesen übersteigenden Energien eintaucht“.22 Es kann kein Zweifel daran bestehen, dass diese Isotopie in Ifigenia cruel von großer Bedeutung ist.

Auf dieser Ebene ließen sich grundlegende Parallelen zur zeitgenössischen Philosophie in Europa herstellen, Parallelen, die Alfonso Reyes durchaus bewusst waren und mit denen er wie schon die Modernisten vor ihm künstlerisch-literarisch spielte. In weitem Maße folgte Reyes der Sichtweise Friedrich Nietzsches, der schon für die Deutung der Antike durch den uruguayischen Modernisten José Enrique Rodó zu einem wichtigen Bezugspunkt geworden war. ${ }^{23}$ Die griechische Tragödie hatte letzterer von ihrem angenommenen Ursprung her als Ausfluss des Dionysischen in eine apollinische Bilderwelt interpretiert. Und auch Alfonso Reyes verwies schon früh darauf, dass für ihn die griechische Tragödie eine „vollständige Repräsentation der Seele in ihrer Dynamik der Leidenschaften (,dinamismo pasional')“ darstelle. ${ }^{24}$

Beim Rückgriff auf die abendländische Antike lässt sich unbestreitbar eine erstaunliche Kontinuität zwischen dem hispanoamerikanischen Modernismo

20 Vgl. Patout, Paulette: Alfonso Reyes, S. 220.

21 Vgl. Melia Sánchez, Ernesto: Estudio preliminar. In: Reyes, Alfonso: Obras Completas, Bd. XX, S. 7-31.

22 Reyes, Alfonso: Obras Completas, Bd. X, S. 353.

23 Vgl. Ette, Ottmar: „Así habló Próspero“. Nietzsche, Rodó y la modernidad filosófica de „Ariel“. In: Cuadernos Hispanoamericanos (Madrid) 528 (junio 1994), D. 48-62.

24 Reyes, Alfonso: Obras Completas, Bd. I, S. 30. 
und den „Vanguardias“ im spanischsprachigen Amerika feststellen. Den vielgestaltigen Proteus in José Enrique Rodós Motivos de Proteo etwa, ${ }^{25}$ verbindet aus uruguayischer Perspektive mit der grausamen Iphigenie in Mexiko keine direkte intertextuelle Verknüpfung, wohl aber eine grundlegende Gemeinsamkeit bezüglich einer Sichtweise der griechisch-römischen Antike, die noch immer als vorbildgebendes kulturelles Modell erscheint. Für Alfonso Reyes wie schon für José Enrique Rodó stellt diese Antike Stoffe und Modelle bereit, die universal gültig oder doch zumindest universal übertragbar, übersetzbar scheinen und ebenso in Europa wie auch in Amerika Aussagekraft für sich beanspruchen können. Beide Autoren gelangten dadurch $\mathrm{zu}$ Texten, die bis heute eine spannungsgeladene Dynamik entfalten, was diese Werke des Modernismo beziehungsweise der „Vanguardia“als (bislang in Europa übrigens wenig ,entdeckte') literarische Perlen der lateinamerikanischen Literaturen auszeichnet.

Die universale (und aus unserer Sicht transareale) Übertragbarkeit hatte Reyes schon in frühen Gedichten, etwa in Elegía de Itaca von 1909, in dem sich ebenfalls das Autobiographische mit der griechischen Antike verbindet, literarisch erfolgreich erprobt. Und selbst noch in der argentinischen Pampa begegnete der Homer-Übersetzer Reyes der Gestalt des Achill, wobei er, sich an den Leser wendend, eher beschwichtigend vorausschickte: „Nur keine Angst vor der Belesenheit. Man muss die Antike mit lebendigen Augen und einer männlichen Seele betrachten, wenn wir den Nutzen der Poesie erhalten wollen." 26

Diese Belesenheit, diese literarische „erudición“, wurde Alfonso Reyes von Beginn an freilich gerade von der lateinamerikanischen Kritik - nicht anders als zuvor bei José Enrique Rodó und später bei Jorge Luis Borges oder Julio Cortázar zum Vorwurf gemacht. Reyes’ „Erudition“ führte in seinen literarischen Texten stets zu komplexen intertextuellen Verweissystemen und einer vielfältigen Vernetzung seiner Texte mit anderen Bezugstexten ebenso in Europa wie in den Amerikas. Schon in den zwanziger und dreißiger Jahren ${ }^{27}$ hielt man ihm unverblümt vor, sich mit Dingen zu beschäftigen, die von der mexikanischen Wirklich-

25 Vgl. Ette, Ottmar: Archipelisches Schreiben und Konvivenz. José Enrique Rodó und seine „Motivos de Proteo“. In: Romanistische Zeitschrift für Literaturgeschichte / Cahiers d'Histoire des Littératures Romanes (Heidelberg) XLII, 1-2 (2018), S. 173-201.

26 Reyes, Alfonso: Obras Completas, Bd. XVII, S. 254.

27 In einem Brief vom 3. April 1925 schrieb der gerade nach Paris umgezogene Reyes an seinen Freund Daniel Cosío Villegas verärgert, aber unbeirrt: „Ich glaubte [...], mir unter den Jüngsten einen liebevollen Umgang verschaffen zu können. Nun aber sieht es so aus, dass einige Junge mich für einen Nestflüchtling (descastado), einen von allerlei müßiggängerischer Belesenheit Besessenen, für einen Aristokraten und ich weiß nicht was halten, und dass sie mich aufspießen und mir andere Grässlichkeiten antun werden.“ In: Enríquez Perea, Alberto (Hg.): Testimonios 
keit meilenweit entfernt seien. ${ }^{28}$ Selbst sein Landsmann Octavio Paz merkte in einer kurz nach Reyes' Tod erschienenen Studie kritisch an, dass sich dieser nicht immer von den „Täuschungen jener Belesenheit“ habe schützen können, „die uns im Neuen von heute die Verrücktheit von gestern sehen lassen““. ${ }^{29}$ Hatte sich der weitgereiste Alfonso Reyes, dessen Freundes- und Bekanntenkreis sich wie das Who's Who der internationalen Kultur- und Literaturszene liest, zu weit von der Realität seines Heimatlandes entfernt? War es denn wirklich so, dass nichts die Heimat der Azteken mit dem fernen Taurerland verband? Wir werden gleich sehen, dass die mexikanische Bedeutungsebene in Ifigenia cruel eine entscheidende Rolle spielte und zu Unrecht Reyes der Vorwurf gemacht wurde, sich mit allzu zahlreichen Bezügen zu anderen Literaturen abgegeben zu haben.

In der Tat wird Ifigenia cruel vom selben Paz, aber heute auch von einer Reihe von Schriftstellern und Kritikern, als einer der Höhepunkte nicht nur des Schaffens Alfonso Reyes', sondern der lateinamerikanischen Literatur insgesamt gefeiert. Sie steht im Schnittpunkt so vieler und so breit gestreuter Texte, dass man angesichts eines solchen intertextuellen Brennspiegels nicht umhin kann, mit der Bewunderung auch die Frage nach dem von diesem lyrischen Theaterstück geforderten Leser zu verbinden. Denn zweifelsohne forderte dieses Versdrama viel von seiner Leserschaft, was die Bezüge zu anderen Mythenbearbeitungen, literarischen Prä-Texten oder Bezugswerken angeht. Zugleich dürfte Alfonso Reyes sicherlich nicht von einer Leserschaft ausgegangen sein, die alle seine intertextuellen Hinweise und Winks hätte einordnen können.

Alfonso Reyes selbst trat dem Vorwurf allzu großer Belesenheit bereits im Mai 1932 in Rio de Janeiro entschieden entgegen, indem er ausführlich seine Überzeugung von einer dialektischen Beziehung zwischen ,dem Mexikanischen ' und ,dem Universalen“ Ausdruck verlieh: „Zu glauben, dass allein das mexikanisch sei, was seinen äußeren Anblick und Mexikanismus ausdrückt und systematisch hervorhebt, ist eine wahrhaft kindische Ansicht. “30 Dies erinnert durchaus an Borges’ witzige Bemerkung, ein Fälscher des Koran würde jede Menge Kamele

de una amistad. Correspondencia Alfonso Reyes / Daniel Cosío Villegas (1922-1958). México, D.F.: El Colegio de México 1999, S. 40.

28 Vgl. etwa Repilado, Ricardo: Contorno de Alfonso Reyes. In: Reyes, Alfonso: Páginas escogidas. Selección y prólogo de Ricardo Repilado. La Habana: Casa de las Américas 1978, S. XV; oder Méndez Plancarte, Gabriel: Resurrección de Ifigenia. In: Páginas sobre Alfonso Reyes (1911-1945). Bd. I. Monterrey: Universidad de Nuevo León 1955, S. 572.

29 Paz, Octavio: El jinete del aire 1889-1959. In: Lectura. Revista crítica de ideas y libros 134 (abril 1960), S. 120.

30 Reyes, Alfonso: Obras Completas, S. $438 \mathrm{f}$. Ähnliche Zitate ließen sich auch von anderen lateinamerikanischen Autoren beibringen, die sich - wie etwa Jorge Luis Borges - mit ähnlichen 
in den Koran tun, um mögliche Leser glauben zu lassen, dass es sich bei diesem Buch um etwas authentisch Arabisches handele. Reyes machte sich über die von seinen Kritikern vorgebrachte Art ,nationalistischer“ Kritik lustig und rief aus: „Die Hellenisten, von der Renaissance bis heute, sind alle Vaterlandsverräter. Die Komparatisten, so etwas wie Doppelagenten, verdienten es, an die Wand gestellt zu werden.“31 Und er fügte hinzu: „Für uns ist die Nation noch etwas Pathetisches, und deshalb verdanken wir uns ihr alle. Im weiten Feld menschlicher Pflicht ist uns ein Teil zugefallen, der uns noch viel zu tun aufgibt. “32

Die in der Folge vorgeschlagene Lesart und Deutung der Grausamen Iphigenie soll versuchen, nicht allein die Bedeutsamkeit dieses Werkes gerade für die mexikanische Realität, sondern auch für die Problematik einer kulturellen Identität in Lateinamerika unter avantgardistischen Vorzeichen aufzuzeigen. Hierbei wird es nicht nur um das (im Sinne von Alfonso Reyes) dialektische Verhältnis zwischen dem Mexikanischen und dem Universalen, sondern mehr noch um die Positionierung dieses avantgardistischen Theaterstückes innerhalb des literarischen und kulturellen Raumes eines transatlantischen Gefüges gehen.

Reyes' impliziter Leser ist gewiss mit der griechischen Antike und den verschiedenen Modellierungen der Orestie aufs Engste vertraut. Die Grausame Iphigenie verlangt aber nicht nur eine genaue Kenntnis der antiken Behandlung des Orest- und Iphigenie-Stoffes, sondern bezieht auch moderne Bearbeitungen, darunter neben Bachofens bereits erwähntem Deutungsmuster vor allem Goethes Iphigenie auf Tauris mit ihrer „heiligen Iphigenie der Humanität“, in ihren äußerst komplexen literarischen Raum mit ein. Reyes selbst hat auf die Mythenkontamination, ${ }^{33}$ aber auch auf die Bezüge des ,Quasi-Sonetts“ des Orest zum spanischen Barocktheater hingewiesen. Mythenkontamination bedeutet letztlich nichts anderes als eine Arbeit am Mythos, wie sie seit Urzeiten bereits in der präklassischen Zeit des Griechentums mündlich und mit der von Paul Zumthor so genannten „mouvance“ geleistet wurde, als man sich die Geschichten erzählte und immer wieder im Gefallen an anderen Geschichten abänderte und verschiedenartig entwickelte. Bisherige literaturwissenschaftliche Analysen konnten die Beziehungen zu Texten von Ramón María del Valle-Inclán oder Stéphane Mallarmé, zu Gustave Flauberts Salammbô und vor allem zu Paul Valérys La Jeune Parque belegen, das nicht von ungefähr zunächst den Titel Gedicht des Gedächt-

Vorwürfen mangelnder ,Argentinität‘ konfrontiert sahen. Heute freilich sind derlei Vorwürfe gegen den Autor von „El escritor argentino y la tradición“ längst verstummt.

31 Ebda.

32 Ebda.

33 Ebda., Bd. X, S. 315. 
nisses (Poème de la mémoire) tragen sollte. ${ }^{34}$ Dies sind allesamt Autoren, welche die schreibenden Zeitgenossen von Reyes faszinierten und zum Anspielungshorizont der Avantgarden zählten.

All dies sollte uns freilich nicht dazu verleiten, Ifigenia cruel als ein in geokultureller Hinsicht dezentriertes Theaterstück zu lesen, das sich aufgrund überwiegend nicht-amerikanischer Quellen in eine extreme Schieflage mit Blick auf amerikanische Identitätskonstruktionen begeben hätte. Die hier erwähnten intertextuellen Beziehungen sind gewiss für ein umfassendes Verständnis dieses bis in die frühen Lektüren Alfonso Reyes' zurückreichenden Textes von größter Wichtigkeit, doch sollten diese Bezüge nicht nur auf die neu entstandenen und vom Werk angebotenen Kontexte bezogen werden, sondern auch auf die paratextuellen und intratextuellen Beziehungsgeflechte, mithin auch auf andere Texte aus der Feder des mexikanischen Polygraphen. Denn wer Intertext sagt, muss auch die Intratexte der jeweiligen Autorin oder des jeweiligen Autors mitbedenken.

Gewiss kann es in unserer Vorlesung nicht darum gehen, allen Spuren dieses intertextuellen wie intratextuellen Spiels mit mehrfachem Boden $\mathrm{zu}$ folgen und die Komplexität dieses wahrlich verschachtelten literarischen Raumes bis in die letzten Details und Winkel zu durchleuchten! Daher können nur einige wenige, für unsere Frage nach der spezifischen Dynamik einer transarealen, also kulturell verschiedenartige Areas miteinander verbindenden Literatur, besonders wertvolle Fäden und Bezugsnetze aufgegriffen werden. Nicht zuletzt aber soll eine Antwort auf die schon seit der Entstehung des Stückes im Raum stehende und oftmals polemisch wiederholte Frage gefunden werden, was die Grausame Iphigenie denn überhaupt mit Mexiko zu tun habe und inwiefern man in dieser Stoffgeschichte und dieser Arbeit am Mythos, die zuvor fast ausschließlich an Europa gebunden war, erstmals eine mexikanische Isotopie entdecken kann.

Mit Blick auf eine mexikanische Isotopie gäbe es verschiedene Annäherungsmöglichkeiten an die Bearbeitung des Stoffes oder die Transposition seiner Handlung. Ausgehen aber möchte ich von jenem Element, auf das Leserin und Leser bei ihrer Beschäftigung mit diesem Höhepunkt der mexikanischen Theaterliteratur zuerst stoßen: Der Titel spricht bereits von der Grausamkeit Iphigeniens und rückt diesen Aspekt ins Rampenlicht. In erster Linie besteht diese „crueldad“ in Iphigenies Tätigkeit als Schlächterin („carnicera“) - so die Formulierung des Autors - im

34 Vgl. neben den bereits genannten Arbeiten insbesondere Patout, Paulette: Réminiscences valéryennes dans „Ifigenia cruel“ d'Alfonso Reyes. In: Hommage à Marcel Bataillon. Paris: DidierErudition 1979, S. 416-437. 
Dienste der Göttin Artemis. Wir nähern uns an dieser Stelle bereits einem amerikanischen Sinnstiftungshorizont an, der gleich von großer Bedeutung sein wird.

Doch noch einmal zurück zu den antiken Modellen, die Alfonso Reyes vorlagen! Hatte Euripides in seiner Iphigenie im Taurerland betont, dass Iphigenie als Griechin selbstverständlich nicht an der Opferung der Fremdlinge beteiligt sei, so legte Reyes, der Euripides in manchen Passagen, etwa im Botenbericht, sehr nahe folgte, gerade auf diesen Aspekt ein erhöhtes Gewicht. Er vermerkte in einem Brief an José María Chacón y Calvo vom Dezember 1922: „Sie heißt Ifigenia cruel [...] und ist mit Axthieben nicht aus dem Holz, sondern aus dem Felsen gehauen. Ich will nicht, dass sie zärtlich ist, nein: Ich selbst bin infolge des Umgangs mit ihr voller Schrammen und Kratzer [...]“.35

Die Grausamkeit ist auf den ersten Blick ein Zivilisationsanzeiger, indiziert also den Grad an zivilisatorischer Entwicklung in einer gegebenen Kultur. Die Grausamkeit der Protagonistin wie des Artemis-Kultes verweist auf den 1915 ebenfalls im spanischen Exil geschriebenen Text Visión de Anáhuac, in dem Reyes schildert, wie sich dem europäischen Blick auf das Andere nicht nur das Wunderbare, sondern auch das Grausame der aztekischen Kultur darbot. ${ }^{36}$ Dies hatte den Konquistadoren wiederum als vordergründiger Anlass und Rechtfertigung der brutalen Durchsetzung ihrer Kultur und ihres Glaubens mit Feuer und Schwert gedient, so dass die vorgebliche ,Grausamkeit“ der Azteken nicht nur negativ belegt, sondern auch jahrhundertelang für europäische Machtansprüche funktionalisiert wurde. Denn eben diese ,Grausamkeit ${ }^{\star}$ - und damit mangelnde zivilisatorische Entfaltung der amerikanischen Kulte - sollte die vermeintlich ,sanfte' Kultur des Christentums heilen, ein Ideologem, das sich etwa sehr stark in Chateaubriands Le Génie du christianisme finden lässt.

Der Mexikaner wies in einem späteren Text darauf hin, dass bereits Montaigne in seinem berühmten Essay Des cannibales angemahnt hatte, dass die im Namen von Religion und Gerechtigkeit begangenen Gräueltaten der Christen gewiss nicht geringer gewesen seien. ${ }^{37}$ Diese These belegt etwa auch die Gegenüberstellung zwischen der taurischen und der griechischen Kultur: Galten die Taurer den Griechen als ,Barbaren', so zeigte im Umkehrschluss die blutige Geschichte des Geschlechts der Atriden die Brüchigkeit solcher Vorstellungen und eine

35 Zit. nach Patout, Paulette: Réminiscences valéryennes, S. 421. Im Übrigen führte Reyes später auch die Verbindung zwischen der Artemis Tauropolos und den ,männerhassenden` Amazonen an; vgl. Reyes, Alfonso: Obras Completas, Bd. XVI, S. 294. Diese Bedeutungsebene ließe sich für eine aktuelle Inszenierung wunderbar hervorheben.

36 Reyes, Alfonso: Obras Completas, Bd. II, S. 15 und 20.

37 Ebda., Bd. XI, S. 59. 
unbedingte Ausrichtung am jeweils eigenen Zivilisationsideal auf. Innerhalb der abendländischen Kultur aber durchschaute bereits ein Montaigne die Ideologiebesetzung der verbreiteten Rede von (der eigenen) ,Zivilisation' und (der fremden) ,Barbarei'. In seinem für die Selbstkritik europäischer Expansion ebenso auf territorialem wie auf intellektuellem Gebiet so wichtigen Essay hatte es geheißen:

Wir können sie also sehr wohl Barbaren heißen, wenn wir sie zu den Regeln des Verstandes in Beziehung setzen, aber nicht, wenn wir sie mit uns vergleichen, da wir sie in jeglicher Art von Barbarei noch übertreffen. Ihr Krieg ist gänzlich edel und großzügig und besitzt so viel Ausrede und Schönheit, wie diese menschliche Krankheit überhaupt besitzen kann. Er findet bei ihnen keine andere Begründung als allein die Eifersucht der Tugend. ${ }^{38}$

Alfonso Reyes nutzte diesen kanonischen, für die Wahrnehmung nicht nur von kultureller Alterität und mehr noch Alterisierung, sondern auch für die des Fremden im Eigenen aufschlussreichen Text für seinen Versuch, gerade das Element der Grausamkeit in einem anderen, nicht mehr vom europäischen Diskurs gelenkten Lichte zeigen zu können. Die Menschenopfer der Iphigenie von Reyes haben - worauf der Autor selbst hinwies, ${ }^{39}$ doch folgte man diesem Hinweis bislang wenig - viel mit aztekischen Opferriten gemein. So fragt der Chor zu Beginn des Stücks, in deutlicher Anspielung auf das ,Herz auf dem Opferstein“ der Azteken, die neue Priesterin: „Wer zeigte dir die Seite, wo der Fremde, / der Schiffbrüchige, sein Herz versteckt hält?“"40 Und selbst in die Statue der Göttin ist diese autochthone, indigene Vergangenheit deutlich eingemeißelt, zeigt ihre Haltung doch „das X / deiner geschmückten und gesalbten Arme““.41 Das X aber ist jenes Zeichen, das für Reyes immer das Symbol MeXikos und der Wegkreuzung der Kulturen und Schicksale gewesen war. ${ }^{42}$ In ihm kristallisiert sich eine kulturelle Markierung, die weniger an einer Essentialität als an transkulturellen Bewegungen - wie etwa den unterschiedlichen Wegen, die zusammenfinden ausgerichtet war.

Leicht ließen sich die Beispiele für Elemente dieser ,aztekischen' Bedeutungsebene oder Isotopie in Reyes' Ifigenia cruel mehren. Sie erlauben es, von einer

38 Montaigne: Essais. Bd. I. Paris: Garnier-Flammarion 1969, S. 259.

39 Vgl. Reyes, Alfonso: Obras Completas, Bd. X, S. 357 f: „Eines Tages stoßen die Taurer zu Füßen ihrer Göttin auf die neue Opferpriesterin, wie sie das Himmlische des Menschenopfers so besingt, wie dies ein Priester der aztekischen Heiligtümer hätte tun können.“

40 Ebda., Bd. X, S. 319.

41 Ebda., S. 325.

42 Vgl. hierzu auch Robb, James W.: Alfonso Reyes al Cruce de los Caminos. In (ders.): Por los caminos de Alfonso Reyes (estudios 2a. serie). México: Centro de Investigación científica y tecnológica de la Universidad del Valle de México 1981, S. 13 ff. 
bislang vernachlässigten ${ }^{43}$ Perspektive aus das Stück neu zu lesen und ihm eine neue Deutung zu geben. Iphigenie ist Griechin - und nicht etwa Taurerin. Sie ist in diesem Sinne - auf göttlichen Ratschluss hin - in einen anderen kulturellen Kontext hineingeworfen, gleichsam deplatziert und deterritorialisiert, gehört folglich zu jenen „Displaced Persons“, zu denen sich Reyes während der Zeit seines Exils selbst rechnen konnte. Sicherlich mag darin ein gutes Stück Autobiographie liegen, kommt in dieser Position doch Reyes' eigener Standort und sein höchst persönliches Lebenswissen und Überlebenswissen zum Ausdruck und zur Geltung.

Reyes hat für seinen poetischen Entwurf die Perspektive der kulturell Verpflanzten und nicht etwa der ,Eingeborenen', der indigenen Kulturen, gewählt und damit seinen intertextuellen Bezugstexten ein Modell entnommen, dessen interkultureller Dimension er nun eine neue transareale Dynamik gab. Reyes nutzte die eigene Deterritorialisierung, um für seine Sicht auf die Amerikas die Perspektive zu wechseln und zugleich die Kopräsenz verschiedener Kulturen in seinem eigenen Land zu begreifen. Mit dem Iphigenie-Stoff wird auch die aus der Antike bekannte Scheidung von Zivilisation und Barbarei übernommen, um sie danach in einen neuen geokulturellen Kontext zu verpflanzen und in Bewegung zu setzen, ja brüchig zu machen. In die Bewegung von Zivilisation und Barbarei ist, wie gleich gezeigt werden soll, jene von Deterritorialisierung und Reterritorialisierung eingeschrieben. Tauris erscheint im Gewand von Mexiko als Land unterschiedlichster Kulturen, die sich in ihrem transkulturellen Entwicklungsprozess wechselseitig befruchten.

Faszinierend ist Reyes' Auseinandersetzung mit der schillernden Titelfigur seines Stückes. Das ,Vergessen“ ihres ersten Lebens hat Iphigenie zu einer willenlosen Sklavin des Opferkultes der Artemis gemacht. Mit der Rückgewinnung ihres Gedächtnisses findet sie einen erneuerten Zugang zu ihrer griechischen Vergangenheit, der ihre dumpfe Entfremdung und Bewusstseinsspaltung - ,ich bin ich und bin die Andere“44 - zu überwinden hilft. Sie versteht sich zunehmend nicht mehr als einer einzigen kulturellen Identität zugehörig, sondern verschiedenen; sie ist nicht mehr die eine, sondern zugleich auch die andere: Gerade darin besteht ihr Reichtum.

43 Eine Ausnahme bildet Roger Bastide, der zwar Reyes' Stück nicht interpretierte, dessen Grundmuster jedoch als ,Archetyp der Problematik kultureller Abhängigkeit begriff; vgl. Bastide, Roger: Iphigénie en Tauride ou Agar dans le désert? (Essai d'analyse critique des mécanismes de pénétration culturelle au Brésil). In: Idéologies, littérature et société en Amérique latine. Bruxelles: Université de Bruxelles 1975, S. 11-30.

44 Reyes, Alfonso: Obras Completas, Bd. X, S. 320. 
Iphigenie ist solange nur willenlose Sklavin der Artemis, im Grunde also einer griechischen Göttin, wie sie nicht mit ihrer eigenen griechischen Herkunft konfrontiert wird. Doch die Anagnorisis der beiden Atriden-Geschwister verändert alles. Die von außen, durch das Auftauchen und die Machtansprüche Orests angestoßene Erinnerung verleiht ihr Macht über die eigene Geschichte, innerhalb derer sie nun Entscheidungen treffen kann. Gleichzeitig läuft sie jedoch Gefahr, erneut in völlige Abhängigkeit zu geraten: diesmal von der Familiengeschichte und der ihr darin zugewiesenen Rolle. Dies wäre die Möglichkeit, wieder zu der $\mathrm{zu}$ werden, die sie war, gleichzeitig aber ihre Fähigkeit zu verlieren, die eine zu sein und zugleich die andere. Durch die Rückkehr würde eine Kreisstruktur vollendet, die die Ausweglosigkeit ihres passiven Gehandelt-Werdens verräumlichte. Zugleich würde die Falle ihrer ursprünglichen Kultur zuschnappen: Sie wäre wieder in ihrer eigenen, ursprünglichen Geschichte angelangt, aber auch wieder eine Gehandelte, nicht länger eine Handelnde.

Denn Iphigenie müsste wieder in eine Rolle schlüpfen, in der sie ohne ihr Zutun aus Gründen der Staatsräson zum Opfertod (in der ,Zivilisation`) geführt worden war, bevor die Göttin Artemis sie errettete und nach Tauris (und damit in die ,Barbarei') entrückte. Sie würde wieder zu einem weithin gehandelten Teil ihrer blutigen Familiengeschichte. Die junge Iphigenie war in ihrem ersten Leben Objekt, nicht Subjekt einer langen und blutigen Geschichte gewesen, in die sie nun die Reise des Orest mit ihrer Kreisbewegung zurückzuholen sucht. Doch sie will nicht zurück in diese Geschichte, die ihr nur den Opfertod brachte und keine eigenen Handlungsräume ließ.

Im Ausbrechen aus diesem Kreis, in der Abwendung von dieser Geschichte durchbricht sie - und nicht wie bei Euripides ihr Bruder Orest - den Fluch, der auf ihrer Familie, auf ihrer ,Rasse` lastet. Sie wird damit zur Agierenden und zur Ausbrecherin aus ihrer „raza“: Mit Bedacht sprach Reyes in seinem Kommentar von „raza“, einem im Spanischen weitaus weniger biologisch als kulturell semantisierten Begriff, der in Hispanoamerika für die Angehörigen der hispanischen Welt verwendet werden kann. Als Handelnde, als Entscheiderin wird sie, wie Goethes Iphigenie, zur eigentlichen Erlöserfigur. Die mexikanische Iphigenie wird allerdings zu einer Erlöserin, die trotz aller Bezüge zu Goethes Entwurf nur wenig mit der Verkörperung jener Humanität der Weimarer Klassik gemein hat. Denn sie ist und bleibt die Grausame, kehrt in ihren Artemistempel - und damit, so dürfen wir annehmen, zu den Opferriten der Göttin Artemis wie der Taurer - zurück. Ihre Reterritorialisierung findet nicht im Griechenland der ,Zivilisation', sondern im Taurerland der ,Barbarei‘, fernab der blutigen Geschichte der Atriden, statt. Doch wer sind hier die ,Zivilisierten“ und wer die ,Barbaren', ein etymologisch im Übrigen griechischer Begriff, der im „Ba-Ba“ die barbarischen Laute einer nicht (den Griechen) verständlichen Sprache nachahmt? 
Genau an diesem Punkt, in ihrem Bekenntnis zum Taurerland, wird sie erneut zur Grausamen, zu einer Iphigenie auf Tauris, die sich für Tauris, für ihre zweite Heimat, und damit scheinbar für das Barbarenland entscheidet. Dem Griechen Orest ist die Entscheidung seiner Schwester unbegreiflich, da sie nach seiner Meinung gegen die ,Zivilisation“ und für das ,Barbarentum‘ optiert. Iphigenie aber wird zur „Hohen Herrin, grausam und rein“ ${ }^{45}$ wie der Chor sie aus gutem Grunde nennt. Ihr Bekenntnis zu dem, was aus griechischer Sicht nur als Barbarei zu bezeichnen wäre, beinhaltet die Abkehr von jener anderen Grausamkeit der sogenannten Zivilisation, von der Montaigne sprach und die uns in der Geschichte der Atriden - und selbstverständlich in der Geschichte unserer abendländischen Zivilisation - ein ums andere Mal entgegentritt. Der Erste Weltkrieg stand mit seinen barbarischen Schlachten in Europa noch immer allen Menschen vor Augen. So befreit die Entscheidung zugunsten der taurischen Barbarei jene Frau, die zuvor nur Objekt, niemals aber Subjekt der Geschichte gewesen war, aus der ununterbrochenen Kette von Mordtaten, welche die Geschichte ihres Hauses, ihrer Herkunft, aber auch der vom antiken Griechenland ausgehenden Zivilisation ist. Aus dieser Geschichte der abendländischen Zivilisation bricht Reyes' Iphigenie aus und wählt ihren eigenen, taurischen, mexikanischen Weg.

Es ist der Ausbruch aus dem Kreis des Griechentums. Orests und Pylades' kreisförmige Reise löst die Verstehens-Bewegung von Iphigenie aus, die sich ihrer eigenen Bewegungslosigkeit als Gehandelte, als Deplatzierte in einem plötzlichen Erkenntnisakt innewird. Das, was Orest als ,alternativlos‘ erscheint, ist nicht ohne Alternativen. Erst jetzt kann die Bewegung der Gehandelten zur Bewegung der Handelnden werden: Iphigenie bleibt im Tempel der Artemis und bestätigt dadurch die aus dem vermeintlichen Zentrum der Zivilisation herausführende Linie - denn Iphigenies Bewegung ist nicht zentripetal, sondern zentrifugal. Damit durchkreuzt sie geometrisch die Rückholungspläne ihres Bruders, die sie in den Teufelskreis der Abhängigkeit, der Dependenz zurückführen würden. In dieser Bewegung entlarvt sie die Selbstverständlichkeit des Blickes Orests, der ,Zivilisierten“ auf die ,Barbaren', mit Hilfe einer anderen, gegenläufigen Lektüre der Theogonie als Barbarei. Die heroische Geschichte einer zunehmenden Zivilisierung des Abendlandes wird in diesem avantgardistischen Theaterstück dekonstruiert.

Iphigenie entscheidet sich damit auch gegen das völlige Aufgesaugt-Werden ihrer gerade erst wiedergewonnen individuellen Identität durch die kollektive, übermächtige Identität des Griechentums, das sie aus der Distanz, aus der Entfernung des Exils auf Tauris plötzlich neu zu sehen gelernt hat. Es ist der Perspektivenwechsel der Deterritorialisierung, der sich als fruchtbar erweist.

45 Ebda., S. 349. 
Es gehört zu den bewusst eingesetzten Anachronismen des Stückes, dass Iphigenie in der Auseinandersetzung mit Orest, der Konfrontation zwischen ,Zivilisation“ und ,Barbarei', die immer schon ein Grundmotiv des Stoffes der taurischen Iphigenie bildete, ein Geschichtsmodell entwirft, an dessen Anfang die Griechen stehen. So wendet sich Iphigenie in für unsere mexikanische Isotopie recht aufschlussreicher Weise an die „Hellenen“:

\author{
Hellenen! \\ Von woher bringt Ihr Fracht an Schicksalen, \\ um an Stränden zu landen, wo die Menschen sterben? \\ Welch aufgeregte Geister habt Ihr Durstigen \\ nach Salz und Öl, die Hunger nach Himmel stillen? \\ Hellenen: Das Glück besteht darin, es nicht zu suchen, \\ und Ihr habt alle Schliche des Meeres versucht. \\ Genügt Euch nicht mehr die Stadt, ausgemessen mit menschlichen Sohlen \\ und, brechend die Grenzen des Himmels, \\ überrascht es Euch jetzt, auf den Stern ohne Gnade zu fallen? \\ Hellenen: Notzüchtiger der Jungfrau der Seele: \\ Die Völker saßen noch, bevor ihr zu gehen begannt. \\ Hier begann die Geschichte und das Erinnern der Übel, \\ bei dem zu konjugieren man vergaß \\ einen einzigen Horizont mit einem einzigen Tal. ${ }^{46}$
}

Dieses Modell geschichtlicher Entwicklung, metaphorisch in das Bild einer fortschreitenden Bewegung gekleidet, entspricht dem Geschichtsdenken des Autors, wie dieser es beispielsweise in Die Weissagung Amerikas ${ }^{47}$ oder Die Kritik in der Epoche Athens ${ }^{48}$ dargestellt hat. Es liefert letztlich den Beweg-Grund für die Übertragung des griechischen Mythos, des abendländischen Paradigmas, auf die aktuelle Situation in Mexiko, dessen „valle“, dessen Hochtal von Anáhuac, hier deutlich eingeblendet wird. Denn auch die mexikanische Geschichte mündet schließlich ein in eine geschichtliche Progression, eine Fort-Bewegung, die Alfonso Reyes zufolge mit der Humanisierung des Menschen im östlichen Mittelmeerraum begonnen hatte. Aber dabei blieb dieses Fortschreiten nicht stehen: Vielmehr entfaltete es sich von Europa aus in alle Himmelsrichtungen.

46 Ebda., S. 330 (Der Begriff „Historia“ erscheint im Original im Sinne eines Kollektivsingulars mit großem Anfangsbuchstaben und wird in der Übersetzung kursiv gesetzt).

47 Ebda., Bd. XI, S. $141 \mathrm{f}$.

48 Ebda., Bd. XIII, S. 46 f. 
Man merkt dieser Geschichtskonzeption wie diesen Versen an, wie tief Alfonso Reyes, ein begeisterter und engagierter Kenner der Schriften Alexander von Humboldts, von Vorstellungen durchdrungen war, welche die Expansion Europas im Sinne einer stetigen Entwicklung hin zu einer die ganze Menschheit sukzessiv erfassenden Weltgeschichte deuteten. Deutlich klingen in dieser Stelle Vorstellungen einer „Translatio Imperii“ mit, einer Westwanderung der Reiche: die frühneuzeitliche Vorstellung also, dass ein Weltreich das andere ablöst und die generelle Bewegung der Reiche nach Westen führt.

Kaum ein Text brachte diese Bewegung und die mit ihr verknüpfte Hoffnung deutlicher zum Ausdruck als jene Passage in Alexander von Humboldts zweitem Band des Kosmos, die - fraglos mit größerer historischer Tiefenschärfe - unter dem Titel „Hauptmomente einer Geschichte der physischen Weltanschauung“ einen Prozess von beeindruckender Linearität entwarf:

\footnotetext{
Die Form des dreimal verengten Mittelmeeres hat einen großen Einfluß auf die früheste Beschränkung und spätere Erweiterung phönicischer und griechischer Entdeckungsreisen gehabt. Die letzteren blieben lange auf das ägäische und auf das Syrtenmeer beschränkt. Zu der homerischen Zeit war das continentale Italien noch ein „unbekanntes Land“. [...] Was aber, wie schon oft bemerkt worden, die geographische Lage des Mittelmeeres vor allem wohlthätig in ihrem Einfluß auf den Völkerverkehr und die fortschreitende Erweiterung des Weltbewußtseins gemacht hat, ist die Nähe des in der kleinasiatischen Halbinsel vortretenden östlichen Continents; die Fülle der Inseln des ägäischen Meeres, welche eine Brücke für die übergehende Cultur gewesen sind [...]. Durch alle diese räumlichen Verhältnisse offenbarte sich in der anwachsenden Macht der Phönicier und später in der der Hellenen, in der schnellen Erweiterung des Ideenkreises der Völker der Einfluß des Meeres als des verbindenden Elementes. ${ }^{49}$
}

Die Humboldt'sche Darstellung entwickelt so jene fortschreitende Bewegung der europäisch-abendländischen Expansion, die dann im 15. Jahrhundert „die unabänderliche Bewegung nach einem vorgesteckten Ziele offenbaren“ sollte. Auf Grund des Übergreifens dieser alles erfassenden Bewegung von Europa nach Amerika konnte der Übergang vom 15. zum 16. Jahrhundert für den Verfasser des Kosmos zur entscheidenden „Uebergangsepoche“ werden, „welche beiden, dem Mittelalter und dem Anfang der neueren Zeit, angehört“.$^{50}$ Der passionierte Humboldt-Leser Reyes konnte einer solchen Vision der Geschichte mit ihrer geradezu zwangsläufigen Konsequenz im Ablauf vieles abgewinnen.

Der östliche Mittelmeerraum ist - in dieser gleichsam im Zeitraffer beobachteten Vision der Menschheitsgeschichte - nach Amerika übergesprungen, die

49 Humboldt, Alexander von: Kosmos, Bd. II, S. 152 und 154.

50 Ebda., S. 266. 
Präsenz des griechischen Mythos in der amerikanischen Welt damit gleichsam geschichtsphilosophisch fundiert. Zudem geben die Karavellen des Kolumbus, die stets einer Kreisbewegung mit der notwendigen Rückkehr nach Europa zu folgen versuchten, jene Bewegungsfigur vor, der auch das Schiff von Orest und Pylades, den Gesandten der Zivilisation im barbarischen Taurerland, wo Menschenopfer an der Tagesordnung waren, gehorcht. Die territoriale, politische und kulturelle Expansion des Okzidents liefert die geschichtliche Grundlage dafür, dass noch an seiner westlichsten Grenze die Figuren der griechischen Antike gegenwärtig werden konnten. So entfaltet sich in Alfonso Reyes' Schriften eine Vision abendländischer Expansion, der es an Stringenz und Konsequenz nicht mangelt.

Freilich: Die mexikanische Geschichte und die mexikanische Kultur gehen nicht restlos in dieser Bewegung, in dieser vorgeblichen, im Übrigen bisweilen schon von Humboldt recht skeptisch betrachteten Entfaltung von Humanität und Weltbewusstsein auf. Denn es handelte sich dabei ohne jeden Zweifel um eine Analyse aus europäischem Blickwinkel, der es nicht an Logik fehlte, die zugleich aber auch andere Perspektiven ausschloss. Diese anderen Blicke, diese anderen Logiken verschwinden nicht in diesem expansiven Wirbel, der vom östlichen Mittelmeer, von Mesopotamien ausgeht!

All dies bildet den Hintergrund eines Verständnisses der Entscheidung Iphigenies, sich aus dieser Geschichte von Fortschritt und Expansion griechischer (und damit abendländischer) Zivilisation $\mathrm{zu}$ verabschieden und sich einer anderen Logik anzuvertrauen. Die Findung der individuellen Identitätskonstruktion Iphigenies vollzieht sich erst in der Auseinandersetzung mit dem Anderen, das auch das Eigene ist: Orest, die griechische Zivilisation, aber auch die Welt der Taurer, welche für die Griechen vom ersten Augenblick an im Zeichen der Grausamkeit steht. Erst aus der Kenntnis der eigenen Geschichte wird diese andere Geschichte ihrerseits steuerbar, verliert ihre blinde Allgewalt: Aus der Zugehörigkeit zu zumindest zwei kulturellen Welten, zwei kulturellen Areas entfaltet sich die transkulturelle Komplexität einer Persönlichkeit, für welche Iphigenie die Chiffre darstellt.

Es sei zumindest am Rande vermerkt, welch starke existentialistische Aufladung in der Entscheidung, der bewussten Wahl der Iphigenie, philosophisch wie literaturgeschichtlich verborgen liegt. Jean-Paul Sartres Die Fliegen schwirren unverkennbar in der Luft und lassen Reyes' Iphigenie im Bannkreis von Bearbeitungen griechischer Mythen erscheinen, welche gerade auch die zentralen Jahrzehnte des 20. Jahrhunderts in den Literaturen der Welt bestimmen sollten. Die Beherrschung des eigenen Schicksals setzt die Rememorierung voraus, und diese erfolgt im Exil, im fernen Tauris, aus ex-zentrischer Perspektive. 
Es ist das Meer, das in Humboldts Sinne verbindende Element, ${ }^{51}$ das die Botschaft überbrachte: „Oh Meer, dein war die Botschaft.“52 Es ist das Meer, das am Ende des Stückes zweimal angerufen wird und für die Erinnerung und damit das Leben steht. Und es ist das Meer, das Orest nach Tauris brachte, ihn aber auch wieder nach Griechenland in ,seine‘ Welt zurückführen wird. Die Entscheidung Iphigenies, mit der der auf allen lastende Fluch und die Kette der Greueltaten gebrochen werden wird, ruht auf der Kenntnis der eigenen Herkunft und verwandelt das Exil in Heimat. Aus der blind ihrem Schicksal und der vorgegebenen Bewegung Folgenden ist die ihr Schicksal Gestaltende, eigene Bewegungen Bestimmende geworden, die sich zugleich auch der übermächtigen Präsenz der Männer erwehrt und ihren eigenen Raum schafft. Iphigenie entflieht der phallogozentrischen Welt der Griechen und wählt aus dem Bewusstsein ihres Griechentums eine differierende Logik, welche letztlich eine Logik von größerer Weite ist.

Auf der im Text durchgängig vorhandenen ,mexikanischen' oder ,lateinamerikanischen' Bedeutungsebene gelesen bedeutet dies, dass die Verwandlung des Exils in Heimat, das volle Bekenntnis zur eigenen Situation, auf einer vollen Kenntnis der eigenen Kultur und Geschichte beruhen muss. Es geht gerade nicht um ein Vergessen des Eigenen, schon gar nicht um ein Verdrängen der eigenen Prägung, welche sich nur wieder in der Freud'schen ,Wiederkehr des Verdrängten` Luft schaffen und mit verstärkter Gewalt zurückschlagen würde. Ein Prozess der Deterritorialisierung geht so in einen weiteren der Reterritorialisierung über, der in Iphigenies Ausruf „¡No quiero!“ - „Ich will nicht!“ - gipfelt. Die ersehnte Reterritorialisierung vollzieht sich nicht als Rückkehr zum alten Eigenen, sondern als Hinwendung zum Fremden, das zum Eigenen geworden ist, ohne das Fremde doch gänzlich abzustreifen. Eine kulturelle Identitätskonstruktion zeichnet sich jenseits einer scheinbaren Homogenität ab, eine transkulturelle Logik, die zugleich in einem viellogischen Verständnis von Kultur wurzelt.

Eine umfassende Identitätsfindung kollektiver Art setzt, so dürfen wir Alfonso Reyes' Position deuten, sowohl die Beschäftigung mit der autochthonen Geschichte als auch mit der Geschichte der Kolonialisierung voraus. Sie kann sich weder allein auf das indigene noch allein auf das europäische Element beschränken. Gerade hierin erblickte Reyes das Spezifische der mexikanischen Kultur als Kreuzung verschiedener kultureller Wege: als Wegekreuz der Kulturen. Im Pariser Exil hatte der Mexikaner den Unterschied zwischen dem quasi geschichtslosen Charakter ,neuer' Länder wie Argentinien (wo die indigene Bevölkerung im 19. Jahrhundert überwiegend ausgerottet oder ver-

51 Vgl. hierzu auch Kapitel 4.

52 Reyes, Alfonso: Obras Completas, Bd. X, S. 349. 
drängt worden war) und der Bedeutung der indigenen Geschichte für Länder wie Mexiko (oder etwa die Andenländer) erkannt. ${ }^{53}$ Im Exil wurde er sich des komplexen, viellogischen und transkulturellen Charakters seines Heimatlandes zunehmend bewusst. Er knüpfte an diese Einsicht die Hoffnung, dass die europäische Kultur in der Auseinandersetzung mit dem autochthonen Amerikanischen neu befruchtet werden könne. ${ }^{54}$ Es ging ihm folglich um eine offene, weite und zugleich viellogische Konzeption ebenso der individuellen wie der kollektiven Suche nach adäquaten Identitätskonstruktionen. Eben dies sollte die weitere Entwicklung im Lateinamerika des 20. und frühen 21. Jahrhunderts vorgeben und vorstrukturieren.

Andererseits war es gerade die koloniale Geschichte, die es laut Reyes den Ländern von Nuestra América - er griff hier sehr bewusst den Martí'schen Begriff auf - ermöglichte, nicht nur im Bereich der Literatur, sondern der Kultur insgesamt eine übergreifende Synthese herzustellen: „Wir sind eine Rasse menschlicher Synthese. Wir sind der wahre historische Saldo. " ${ }^{\text {55 }}$ Derartige Konzepte fanden im Nachklang zu José Martí bei einigen der herausragenden Intellektuellen Mexikos ein ähnlich begeistertes Echo - selbst die Vorstellung einer „raza cósmica“, einer „Kosmischen Rasse“, in der alle Kulturen des gesamten Planeten zusammenfließen, war eine der zentralen Vorstellungen, welche etwa der Mexikaner José Vasconcelos für seine Landsleute in jenen Jahren umschrieb. Mexiko schien ein Ort globaler Zusammenführung, universaler Synthese, aber auch einer Symbiose, eines Zusammenlebens, einer weltweiten Konvivenz zu sein.

Auf Grund der historischen Erfahrung des Weltkrieges sowie später des Spanischen Bürgerkrieges vertrat Alfonso Reyes, wie damals eine Vielzahl lateinamerikanischer Intellektueller wie die erwähnten José Enrique Rodó, Pedro Henríquez Ureña oder José Vasconcelos, die Auffassung, dass der Geschichtsverlauf den amerikanischen Kontinent zum Ort einer (im Bloch'schen Sinne) konkreten Utopie gemacht habe. Einer Utopie, die den Lateinamerikanern moralische Verpflichtung sein müsse:

Zum gegenwärtigen Zeitpunkt lässt sich der Kontinent von einer Hoffnung umfassen, und er bietet sich Europa als ein Reservoir an Humanität an. Entweder ist dies der Sinn der Geschichte, oder es gibt keinen Sinn in der Geschichte. Ist dem nicht so, dann muss dem künftig so sein, und wir Amerikaner, wir alle wissen dies. [...] Amerika ist eine Utopie. ${ }^{56}$

53 Vgl. hierzu Patout, Paulette: Alfonso Reyes, S. 82.

54 Reyes, Alfonso: Obras Completas, Bd. XI, S. 104.

55 Ebda., Bd. XI, S. 134.

56 Ebda., Bd. XI, S. 60. 
Derlei Aussagen von Alfonso Reyes waren von einem breiten Selbstvertrauen, aber auch von einer Überzeugung getragen, dass Lateinamerika in Zeiten, in denen Europa im Krieg zu versinken drohte, künftig eine wunderbare Zukunft offenstehen werde. Der Raum als Objekt europäischer Expansion ist zum Raum einer Hoffnung planetarischen Ausmaßes geworden: als Reservoir einer Humanität, die man in der vermeintlichen Wiege der Humanität, in Europa, vergebens suchen würde. Das Tor zur Zukunft stand für die lateinamerikanischen Staaten weit offen, ihr weiterer Fortschritt - auch im Sinne einer konkreten Utopie - schien sicher und ganz gewiss! Dies war ein Futurismus gänzlich anderer Art als der, den wir bei den italienischen Futuristen beobachten konnten: Er ging einher mit einem ungeheuren kulturellen Optimismus, mit einem Vertrauen in die in Lateinamerika zusammenfließenden Kulturen der Welt.

Amerika erschien in diesem Zusammenhang - gewiss in einer langen Traditionslinie, die von Christoph Kolumbus und Thomas Morus bis zu Jean Baudrillard reicht, seit der zweiten Hälfte des 18. Jahrhunderts aber vorwiegend in den Norden der Hemisphäre verlagert wurde - als Kontinent der Zukunft. Alfonso Reyes rückte vor allem den lateinamerikanischen Teil des Kontinents in die starke Position einer Hoffnung auf Menschlichkeit, Menschenwürde und Humanität, die andernorts in Barbarei zu versinken drohte oder längst schon versunken war. Das Taurerland ist zum Hort einer Kultur der Menschheit geworden, zum Sitz einer ,kosmischen Rasse‘, die den ,historischen Saldo' aller Zeiten und Epochen, aller Geschichten und Kulturen, die in ihr gleichzeitig präsent würden, repräsentiert. Die Bürde der langen kolonialen Vergangenheit schien für immer getilgt.

Doch wie bei der Verwandlung der Erinnyen in Eumeniden in Aischylos' Orestie das Alte nicht ausgemerzt und verdrängt, sondern integriert wird und seinen Platz in der neuen Gesellschaft erhält, so darf auch hier das Vergangene, und vor allem die Kolonialgeschichte, nicht aus dem kollektiven Bewusstsein verdrängt werden. In einer Zeit, in der das Studium der spanischen Geschichte und Kultur in Mexiko nur noch nachgeordnet betrieben wurde, forderte Alfonso Reyes in einem Artikel aus dem Jahre 1921, also kurze Zeit vor der Niederschrift seiner Ifigenia cruel im spanischen Exil, zu intensiverer Beschäftigung, zur Verstärkung der Bande mit Spanien nach einem Jahrhundert des beiderseitigen Vergessens auf. Eine Rückbesinnung mit Zukunftsperspektive, die für beide Seiten von gleich großer Bedeutung sei:

Wie Amerika nie den Sinn seines Lebens völlig entdecken wird, solange es nicht Stück für Stück sein „spanisches Bewusstsein“ wiederherstellt, so gibt es für Spanien keine bessere Aufgabe in der Welt, als seine Rolle als große Schwester der Amerikas wieder anzunehmen. ${ }^{57}$

57 Reyes, Alfonso: Obras Completas, Bd. IV, S. 572. 
In Alfonso Reyes' Ifigenia cruel spielt die zweifellos entscheidende Rolle das menschliche Gedächtnis. Mit der Funktion dieses Gedächtnisses steht und fällt der gesamte Prozess der Neuorientierung Iphigenies. Wie auf individueller, so ist auch auf kollektiver Ebene das Gedächtnis für Lebens- und Identitätsfindung von entscheidender Bedeutung: „Vielleicht besteht das unmittelbare Ziel des Lebens darin, einen Brunnen von Erinnerungen zu schaffen. " ${ }^{58}$ Hieran schließt sich auch unmittelbar die Aufgabe der Literatur an: Denn ist nicht sie es, die mit Hilfe zahlreicher intertextueller Verweise einen wirklichen Brunnen der Erinnerung schafft und vielleicht mehr noch ein Netzwerk an Erinnerungen, zwischen dessen Knoten sich der Mensch bewegt? Ist es nicht die Literatur, die damit von essentieller Bedeutung für das Menschsein in einem vollständigen Sinne steht? Schafft nicht die Literatur eine Welt, die uns immer wieder vor neue Entscheidungsmöglichkeiten stellt und uns als ganze Menschen fordert?

Die entscheidende Rolle des (literarischen) Gedächtnisses, der Erinnerung, für die freie Selbstbestimmung sowohl auf individueller wie auf kollektiver Ebene wollte Alfonso Reyes durch seine Gestaltung des Iphigenie-Mythos unterstreichen, übrigens sehr wohl im Sinne einer „moralischen Allegorie“.59 Jenseits seiner Allegorese besaß Reyes eine klare Vorstellung von der besonderen Position und Rolle des lateinamerikanischen Schriftstellers, der auf Grund der politischen und sozialen Verhältnisse seines Heimatlandes die Spezialisierung und Beschränkung auf einen rein literarischen Bereich im Gegensatz zum europäischen Schriftsteller in jenen Jahren noch nicht kannte, denn:

Alles trägt dazu bei, den Schriftsteller in der ersten Reihe zu verorten. Adel verpflichtet. Es darf keine Elfenbeintürme geben. Der Literat geht über sich selbst hinaus und engagiert sich einmal mehr, einmal weniger in den Bestrebungen im öffentlichen Dienste, die ihn anziehen und fordern. ${ }^{60}$

Dieser besonderen Verantwortung des lateinamerikanischen Schriftstellers, der nicht allein im literarischen, sondern auch im intellektuellen und politischen Feld aktiv werden sollte, war sich Alfonso Reyes sehr bewusst. Vorgaben, die ganz wesentlich die kommenden Generationen lateinamerikanischer Schriftsteller beschreiben sollten, insbesondere die Autorinnen und Autoren des sogenannten ,Boom‘ der lateinamerikanischen Literaturen. Die Grausame Iphigenie entscheidet sich für die scheinbare Barbarei des Taurerlandes und rettet gerade

58 Zitiert nach Iduarte, André: Alfonso Reyes, S. 18.

59 Reyes, Alfonso: Obras Completas, Bd. X, S. 354.

60 Reyes, Alfonso: Páginas escogidas, Bd. XXII, S. 649. 
dadurch, so gibt uns Reyes zu verstehen, diesen Raum als Reservoir einer Humanität, die sich hinter ihrer Grausamkeit verbirgt. Der Schriftsteller mischte sich damit in eine kulturelle Grundsatzentscheidung ein, die im politischen Bereich mit dem Triumph der Mexikanischen Revolution ein neues Kapitel mexikanischer Geschichte eröffnen sollte.

Die unabdingbare Voraussetzung für die Schaffung einer historischen und kulturellen Wahl zwischen verschiedenen Alternativen ist wie in Ifigenia cruel immer das eigene Geschichtsbewusstsein, so wie es der junge Alfonso Reyes, das Mitglied des Ateneo de la Juventud, in seinem frühen Essay Visión de Anáhuac bereits entdeckt hatte. Lassen wir ein letztes Mal den mexikanischen Autor selbst zu Wort kommen! Reyes griff in diesem Text sowohl auf die Náhuatl-Kultur, auf die Kultur der Mexica, als auch auf die Geschichte der europäischen Expansion zurück. Mit letzterer beginnt auch sein Essay über das mexikanische Epochenjahr 1519, in dem die siegreichen spanischen Konquistadoren auftachten:

\begin{abstract}
Reisender: Du bist zur durchsichtigsten Region der Luft gekommen.
In der Epoche der Entdeckungen erschienen Bücher voller außergewöhnlicher Nachrichten und gefälliger geographischer Erzählungen. Die Geschichte, die nunmehr gezwungen war, neue Welten zu entdecken, tritt über ihr klassisches Flussbett hinaus, und so überlässt das politische Faktum seinen Posten den ethnographischen Diskursen und dem Gemälde der Zivilisationen. Die Geschichtsschreiber des 16. Jahrhunderts bestimmen den Charakter der jüngst aufgefundenen Länder, so wie sie in den Augen Europas erschienen: von der Überraschung beeinflusst und bisweilen übertrieben. Der umsichtige Giovanni Battista Ramusio veröffentlicht seine umschweifige Zusammenstellung Delle Navigationi et Viaggi in Venedig im Jahre 1550. Das Werk besteht aus drei In-folio-Bänden, die später getrennt wieder abgedruckt und ebenso üppig wie zauberhaft illustriert wurden. ${ }^{61}$
\end{abstract}

Der Rückgriff von Alfonso Reyes auf die europäischen Chronisten des sechzehnten Jahrhunderts ist ebenso evident wie zukunftsträchtig, wird es doch nicht zuletzt dieser historische Gestus sein, der - verbunden mit der eruditen Art des mexikanischen Poeta doctus - wenige Jahrzehnte später einen Alejo Carpentier zu seinem großen romanesken Oeuvre führen wird. Die Generation des Ateneo de la Juventud stellt die Frage nach Identität, sie stellt sie aber vor allem aus der Verbindung verschiedener Kulturen und vor einem Hintergrund profunder Kenntnisse abendländischer Traditionen, die mit indigenen Kulturelementen verknüpft werden. Die historische Avantgarde in Hispanoamerika zeigt stets die Absicht, verschiedene kulturelle Pole, vor allem aber die abendländischen und die spezifisch amerika-

61 Reyes, Alfonso: Visión de Anáhuac. In (ders.): Ensayos. La Habana: Casa de las Américas 1972, S. 3. 
nischen, aufeinander $\mathrm{zu}$ beziehen, miteinander zu verschmelzen und daraus eine neue Identität der Völker wie auch des Schreibens beziehungsweise der Künste selbst zu gewinnen. Wir werden dies im weiteren Verlauf unserer Vorlesung noch bei höchst verschiedenartigen Autorinnen und Autoren feststellen können. Dabei betonte diese Avantgarde immer wieder den indigenen kulturellen Pol, was der hispanoamerikanische Modernismo - sicherlich mit Ausnahme des Kubaners José Martí und eingeschränkt auch des Nikaraguaners Rubén Darío - eher ausgespart hatte. Die historischen Avantgarden in Lateinamerika setzen bezüglich dieser transkulturellen Komponenten - wie wir schon in Ifigenia cruel begriffen hatten - verstärkt eigene Akzente.

Wir sehen hier also einen deutlichen Aspekt avantgardistischer Kunstauffassung. Dies war auch der Grund, warum wir uns mit Alfonso Reyes' Versdrama so ausführlich auseinandergesetzt hatten: Es ist in Reyes' Ifigenia cruel die Arbeit am kulturellen Erbe, am kulturellen Gedächtnis des Abendlandes, das selbstbewusst als das eigene Erbe reklamiert, gleichzeitig aber auch verändert und auf die lateinamerikanischen Bedürfnisse bezogen wird. So darf es heute auch als bedeutungsvolles Detail erscheinen, dass 1925 bei einer ersten Lesung des Stückes im Hause des ecuadorianischen Gesandten in Paris bolivianische QuenaFlöten an die Stelle griechischer Panflöten traten. ${ }^{62}$ Denn in den Andenländern stellte sich die Frage nach der Integration der indigenen Kulturen in eine wie auch immer geartete, Nationalkultur‘ ähnlich dringlich wie in Mexiko. Dass ganze hundert Jahre später diese Frage zwar weiter fortgeschritten, aber letztlich noch immer ungelöst ist, hätte sich wohl keiner der bei dieser Aufführung Anwesenden träumen lassen. Bisweilen fällt es schwer, dauerhafte (und nicht nur ephemere) Fortschritte auf diesem Gebiet überhaupt zu konstatieren ...

Freilich stößt der Rückgriff auf und die Arbeit am antiken abendländischen Mythos aus lateinamerikanischer Perspektive auch an seine Grenzen! Die für die Zuhörerschaft sicherlich überraschende Schlusswendung mit der Weigerung Iphigenies, an der Seite Orests nach Griechenland zurückzukehren, ist von Reyes erst spät und autobiographisch teilmotiviert hinzugefügt worden. Sie macht, wie gezeigt werden sollte, die eigentliche Bedeutung des Stückes aus, führt aber gleichzeitig eine Reihe fruchtbarer Widersprüche herauf, die die Begrenzung des Reyes'schen Entwurfes aufzeigen.

Denn die Entscheidung Iphigenies ist, diskursiv betrachtet, eine reine Verweigerung. Die „conchas huecas“ des „no quiero“ am Ende lassen die Zukunft des Taurerlandes offen: Der durch die freie Entscheidung Iphigenies eröffnete Raum wird nicht mehr konstruktiv ausgefüllt. So bleibt beispielsweise unklar, ob

62 Vgl. hierzu Reyes, Alfonso: Obras Completas, Bd. X, S. 12. 
die Flucht in den Tempel, wie es Reyes auch im Selbstkommentar nahelegte, mit der Beibehaltung der Menschenopfer im Taurerland gleichbedeutend ist. Oder ob - wie eigentlich zu erwarten bei dem mexikanischen Humanisten - von Iphigenie wie in Goethes Bearbeitung ein humanisierender Einfluss ausgeht, der sich gewiss am Ende des Stückes in der Milde und Großherzigkeit des Toas gegenüber den Griechen ein wenig zu erkennen gibt.

Entscheidend war zwar für Reyes das willentliche Ausbrechen der Protagonistin aus einer Kette der Fatalität wie des Gehandelt-Werdens und weniger der weitere Entwicklungsgang und Lebensweg, doch zeigt sich anhand der Negativität der Neubestimmung die Grenze der Tragfähigkeit des antiken Mythos für einen Identitätsentwurf Mexikos wie Lateinamerikas insgesamt. Der Rückgriff auf das antike abendländische Paradigma lässt nicht zuletzt offen, wie sich die weitere Entwicklung zwischen Griechenland und Tauris, zwischen alter und neuer Heimat, alter und im Entwurf neuer Kultur gestalten wird. Orests Segel, soviel steht fest, sind am Horizont verschwunden.

Iphigenie auf Tauris als Paradigma kultureller Abhängigkeit und deren möglicher Überwindung - eine Interpretation des antiken Mythos, wie sie nur aus der spezifischen Situation einer sich aus ihrer Dependenz befreienden Literatur geleistet werden konnte. Die Asymmetrie der literarischen Beziehungen innerhalb des widersprüchlichen transatlantischen Raumes der europäischen und lateinamerikanischen Literaturen zeigt sich am Rückgriff, vor allem aber an der Gestaltung des abendländischen Mythos. Unbestreitbar und zugleich höchst beeindruckend ist der Wille, vitalen und nicht musealen Anteil zu nehmen an der abendländischen Kulturtradition und sich auf diese Weise einzuklinken in ein sich abzeichnendes System der Literaturen der Welt, das sich ab der zweiten Hälfte des 20. Jahrhunderts mit seinen unterschiedlichen Logiken ausprägen sollte. Alfonso Reyes darf auf diesem Gebiet zweifellos als ein Pionier gelten!

In Reyes' kreativer Arbeit am (abendländischen) Mythos, in der Vielschichtigkeit und Widersprüchlichkeit seiner taurischen Iphigenie, wird aus der Fragwürdigkeit der literarischen Transposition eine der faszinierendsten und aufschlussreichsten Bearbeitungen des Iphigenie-Stoffes in der Moderne. Sie gerät zu einem wahren Gegenentwurf, zu einer lateinamerikanischen Iphigenie, die dem Mythos der europäischen Antike neue und brennende Fragen aus einer mexikanischen und gewiss amerikanischen Perspektive stellt. In Europa allerdings hat man diese Arbeit der außereuropäischen Literaturen am literarischen Erbe der Alten Welt und dessen kreative Anverwandlung noch immer kaum zur Kenntnis genommen. Was freilich nicht so sehr ein Problem der lateinamerikanischen Literaturen, wohl aber der Literaturen - und des mit ihnen verbundenen Weltbewusstseins Europas ist. 